\title{
Las comisarías del Santo Oficio en la Audiencia de Filipinas. Conflictividad y comunicaciones en un espacio inquisitorial periférico, 1583-1784
}

The Comisarias of the Holy Office in the Audience of Philippines. Conflict and Communications in a Peripheric Inquisitorial Space, 1583-1784

PEDRO MIRANDA OJEDA

https://orcid.org/0000-0003-1881-8778

Universidad Autónoma de Yucatán

pmojeda@correo.uady.mx

\section{RESUMEN}

Las enormes distancias geográficas y la lentitud en las comunicaciones entre México y las Filipinas constituian un problema en la provisión de oficios. De ahi que, desde el siglo XVI hasta el siglo XVIII, hubo varios intentos por establecer un tribunal del Santo Oficio en Manila que al final no prosperaron. Con el objetivo de subsanar todos estos inconvenientes, el tribunal inquisitorial de México implementó una serie de medidas. La primera consistió en otorgar una concesión especial a la comisaría de Manila para poder aplicar sentencias en delitos menores. La segunda fue establecer una división territorial de las comisarias diocesanas con la finalidad de ampliar su presencia a la mayoría de las poblaciones de las islas. Por último, el nombramiento simultáneo de tres comisarios que pudieran sustituir en cualquier momento al propietario en caso de ausencia.

Palabras clave: Filipinas, distancias, comunicación, Santo Oficio, comisarias 


\section{ABSTRACT}

The enormous geographical distances and slowness in communications between Mexico and the Philippines constituted a problem in the provision of trades. The Tribunal of the Holy Office of New Spain, on whom they depended on to carry out an effective inquisitorial activity, had to implement a series of actions with the aim of correcting all these inconveniences, Mexico's inquisitorial court implemented a series of measures. The first was to grant a special concession to the Manila comisaria to be able to apply sentences in minor crimes. The second was to establish a territorial division of the diocesan comisarias to expand their presence to most of the populations of the islands. Finally, the simultaneous appointment of three comisarios who could replace the owner at any time in case of absence.

Keywords: Philippines, distances, communication, Holy Office, comisarias

$\mathrm{L}$ a conquista de las islas Filipinas amplió el territorio inquisitorial no estuvo exenta de conflictos debido a la intervención de Manila. La compleja coyuntura describe las numerosas dificultades y desavenencias que los inquisidores de México hubieron de enfrentar con las autoridades políticas y eclesiásticas filipinas. Los conflictos, estrategias, soluciones, etc. de las comisarías filipinas pueden advertirse en la documentación. Es así que el trabajo de campo, en distintas temporadas, en el Archivo General de la Nación (México) y en el Archivo Histórico Nacional (Madrid), ambos en la sección Inquisición, tenga un papel destacado. También ha sido categórica la documentación localizada en distintas secciones del Archivo General de Indias (Sevilla).

La historiografía inquisitorial ha sido fundamental para comprender y explicar las singularidades de las comisarías de las Filipinas. De ahí la importancia del planteamiento desarrollado a partir de dos conceptos principales. El análisis de las dificultades en el intercambio de información entre los inquisidores de México y los comisarios de Manila, que caracterizó la singularidad inquisitorial de las islas, puede observarse desde la óptica de los conceptos imperio de archipiélagos y gobierno de 
papel, desarrollados por Elizabeth Montañez ${ }^{1}$ y José Araneda Riquelme, ${ }^{2}$ respectivamente, porque permiten examinar las complicaciones administrativas de la gobernanza de los territorios ultramarinos.

Estos conceptos son útiles para comprender el contexto de las comisarías de la Audiencia de Manila. Cuando se aplican en la historiografía inquisitorial de las Filipinas, permiten una comprensión más adecuada de la complejidad vivida. Desde el punto de vista de la distancia, también se define el trabajo de Ostwald Sales Colín cuando discute las causas que contribuyeron al fracaso de creación de un tribunal en Manila a mediados del siglo XVII, aunque también concede importancia a las dificultades de las comisarías y los conflictos socioétnicos habidos en las islas. ${ }^{3}$ No obstante, el estudio de Miguel Rodrigues Lourenço constituye la contribución más completa sobre los distintos intentos de creación de un tribunal en las Filipinas, con un minucioso trabajo de archivo que permite una mejor comprensión de la situación que conllevó al fracaso de las negociaciones para su establecimiento en el siglo XVII. ${ }^{4}$

Aun cuando a principios de siglo XX, Charles H. Cunningham publicó un trabajo dedicado a analizar la conspiración de las élites contra el gobernador Diego de Salcedo, también consideró importante destacar una de las primeras propuestas de creación del tribunal. ${ }^{5}$ De todos estos trabajos realizados sobre la Inquisición en las Filipinas, es indudable el enorme valor que tiene la obra clásica de José Toribio Medina, El Tribunal del Santo Oficio de la Inquisición en las islas Filipinas, publicada en 1899. A pesar de su antigüedad, constituye una referencia obligatoria de cualquier investigación porque reconstruye toda la historia inquisitorial filipina, utilizando para ello cientos de fuentes primarias entonces desconocidas. Por supuesto, Medina describe con minuciosidad los momentos más críticos en las islas, nombramientos de comisarios, los conflictos por

\footnotetext{
1 Araneda Riquelme 2020: 19.

2 Ib.: 17-18.

3 Sales Colín 2000.

4 Rodrigues Lourenço 2019.

5 Cunningham 1918.
} 
competencias, iniciando con la complicada situación vivida durante el establecimiento de la primera comisaría diocesana en Manila. ${ }^{6}$

En este tenor, el estudio de los años formativos de la comisaría de Manila y los conflictos que se sucedieron son analizados por Fernando Palanco Aguado. Desde un punto de vista, es un trabajo importante porque introduce elementos y documentación para explicar la difícil situación y el enfrentamiento entre el obispo de Manila y los inquisidores de México. ${ }^{7}$

Desde esta perspectiva, la historiografía ha proporcionado algunos de los elementos que se analizarán en este estudio. Por lo tanto, se considera que los contratiempos administrativos de las comisarías de la Audiencia de Manila fueron una consecuencia directa de la demora de las comunicaciones. La lejanía entre ambos territorios provocó que la correspondencia no fluyera de manera frecuente, restringiendo la continuidad y la actividad de los comisarios. Los conflictos entre autoridades también propiciaron repetidas disputas políticas por competencias jurisdiccionales, debido a las limitadas facultades que tenían los comisarios de las islas.

En este sentido, el tema de este artículo es el análisis de las intenciones de la corona española de instalar un Tribunal del Santo Oficio en Manila que contribuyera a la solución de las discordias y a ejercer un control efectivo del orden administrativo de las distintas comisarías. Desde esta óptica, también se desprende el análisis de las distintas medidas implementadas por México para resolver algunos de los problemas más complejos derivados de la comunicación a distancia: la concesión de poderes especiales para poder aplicar en Manila sentencias consideradas menores, los cambios territoriales en las jurisdicciones de las comisarías diocesanas y la introducción de comisarios de primer, segundo y tercer lugar.

\footnotetext{
6 Medina 1899.

7 Palanco Aguado 2018.
} 


\section{LOS AÑOS FORMATIVOS}

La instalación del Tribunal del Santo Oficio de México se formalizó el 4 de noviembre de 1571. Aun cuando las reales cédulas de fundación y jurisdicción, 25 de enero de 1569 y 16 de agosto de 1570, respectivamente, serían piezas angulares para la formación del tribunal de México, las instrucciones del inquisidor general, Diego de Espinosa Arévalo, dadas en Madrid el 18 de agosto de 1570, constituyeron el conjunto normativo fundacional que estableció los fundamentos de su organización, funcionamiento y jurisdicción. Esta última circunscrita

en la gran ciudad de Temistitlán México y en todas las provincias de la Nueva España, que son de los distritos de las audiencias de México, Guatemala, Nueva Galicia, en que caen el Arzobispado de México y Obispados de Oaxaca, Nueva Galicia, Michoacán, Tlaxcala, Yucatán, Guatemala, Chiapas, Verapaz, Honduras, Nicaragua, y sus cercanías, y en todos los reinos y Estados de la dicha Nueva España y su distrito y jurisdicción. ${ }^{8}$

Esto no quiere decir que el territorio estaba definido. La jurisdicción diocesana se consideraría como eje articulador de los distintos distritos inquisitoriales. Con esta medida, se pretendió la incorporación de todas las arquidiócesis y diócesis, renombradas comisarías diocesanas, que asumirían el control en los asuntos tocantes al Santo Oficio en dicho territorio, exento de la autoridad y competencia del obispo correspondiente. En años inmediatos, la presencia de las comisarías diocesanas fue consolidándose en Nueva España.

En la época fundacional del Santo Oficio, la dominación española todavía era incipiente en Filipinas. De hecho, la ciudad de Manila era de reciente fundación (1571). De tal suerte que el archipiélago, después de ser una gobernación (1565), se convirtió en dependiente de Nueva España cuando fue elevada a la categoría de Capitanía General de Filipinas (1574) y, más tarde, Real Audiencia de Manila (1584). Por obvias razones, en estos primeros años la presencia inquisitorial estuvo ausente en las islas.

${ }^{8}$ Espinosa 1906: 225-226. 
La situación cambiaría con el establecimiento de la primera diócesis filipina, en Manila (1579), sufragánea del arzobispado de México. El primer obispo, fray Domingo de Salazar, llegaría ahí en septiembre de 1581. Durante su estancia en México, incluso había afirmado que en una tierra nueva y con escasa presencia hispana no había necesidad de sus servicios. Sin embargo, apenas iniciadas sus tareas episcopales, también asumió funciones inquisitoriales procediendo en causas de fe. De manera inmediata (1583), los inquisidores de México nombraron al agustino fray Francisco de Manrique como primer «comisario que es o por el tiempo fuere deste Sancto Oficio en la cibdad y obispado de Manila e Islas Filipinas del Poniente», ${ }^{9}$ es decir, su jurisdicción abarcaba los límites políticos de la Audiencia de Manila. Hay que enfatizar que dicho nombramiento, recibido en julio del mismo año, no había sido solicitado por Manrique, sino que fue una estrategia de México para evitar las continuas interferencias del obispo en asuntos tocantes al Santo Oficio. Aun así, el comisario de inmediato nombró a un notario y envió las notificaciones respectivas. ${ }^{10}$ No obstante, el obispo todavía pretendió arrogarse dicha autoridad, evitando hacer entrega al comisario de los expedientes de los procesos iniciados, desautorizando su nombramiento e imponiendo pena de excomunión mayor a quien obedeciera sus mandamientos, con la justificación de que su distrito no formaba parte de la jurisdicción del Santo Oficio. ${ }^{11}$ Esta apreciación del obispo se desprendía de la ausencia de las Filipinas, como jurisdicción inquisitorial, en las reales cédulas de creación y establecimiento del Santo Oficio en Nueva España.

Ante los desagravios de Salazar, la posición del comisario era endeble. A pesar de que, en junio de 1584, se recibieron cartas que revocaron todos los edictos de Salazar, el conflicto aún no se resolvía. En estas cartas, también se designaba a fray Diego Muñoz como sustituto del comisario, en caso de muerte o ausencia, lo cual fue aprovechado por el agustino para emprender su viaje a Macao, pues la evangelización de China constituía

\footnotetext{
9 Rodrigues Lourenço 2020.

${ }^{10}$ Palanco Aguado 2018: 89-90.

${ }^{11}$ Medina 1899: 14-19. También puede verse Coello de la Rosa 2019.
} 
la razón principal de la presencia agustiniana en las Filipinas. ${ }^{12}$ De esta manera, a finales de 1584, Muñoz asumió la comisaría diocesana de las islas, en calidad de interino. Su título tardaría en llegar dos años. ${ }^{13} \mathrm{La}$ escasa actividad inquisitorial, antes de agosto de 1587 , se explica porque el conflicto con el obispo todavía estaba vigente. En esta coyuntura, la controversia se trasladó al Consejo de Inquisición. En una real cédula, firmada en Barcelona el 26 de mayo de 1586, se reconocía que las islas sí formaban parte de la jurisdicción inquisitorial de México y ordenaba al obispo no interferir en los asuntos tocantes al Santo Oficio. De ahí que, a principios de 1587, el diocesano reconociera la autoridad de Muñoz e hiciera entrega de las causas iniciadas. ${ }^{14}$

Después de cuatro años de conflictos por la competencia jurisdiccional, Muñoz asumió plenamente el control de la comisaría de Manila que, por otra parte, implicaba la administración de un enorme territorio, conformado por miles de islas y una población muy dispersa. En efecto, la evangelización constituía una tarea reciente y difícil de realizar, y la imposición de nuevas autoridades inquisitoriales también tenía escasas oportunidades de establecer su dominio sobre los comportamientos desviados. En un territorio de 300000 km², con una población espańola confinada principalmente en Manila, era muy complicado poder controlar a la inmensa mayoría de población china, llamados sangleyes, mestizos y otras etnias asentadas de regiones cercanas que mantenían fuertes vínculos económicos con las Filipinas. ${ }^{15}$

Las visitas de control eclesiástico, inquisitoriales o episcopales, se convirtieron en quimera común. La extensión del territorio y la dispersión de la población no eran los únicos problemas que debían enfrentar las autoridades: comunicaciones internas a menudo inexistentes, difícil circulación entre islas, hostigamiento y resistencia de los nativos, etc. reservaron a las islas como un territorio poco conocido y evangelizado,

\footnotetext{
12 Palanco Aguado 2018: 95-96.

${ }^{13}$ Ib.: 96.

${ }^{14}$ Medina 1899: 24-33.

${ }^{15}$ García-Abásolo 2005: 488-490.
} 
que los agustinos, dominicos, franciscanos y jesuitas no siempre pudieron asumir con la disciplina correspondiente de su hábito.

La insumisión del clero regular hacia sus superiores jerárquicos, por supuesto, tuvo efectos negativos en el ejercicio pastoral a tal grado, que puede decirse que esta insumisión se convirtió en la causa principal del mal gobierno espiritual. La constante intromisión en la jurisdicción real o eclesiástica consistía en pretender resolver conflictos de los indios, publicación de bulas y breves no conocidos por el Consejo de Indias, nombramiento de clérigos sin conocimiento de la autoridad civil o del prelado, obstaculizar la realización de visitas pastorales, etc. ${ }^{16}$ En 1769 , por ejemplo, el Consejo de Inquisición reconvino al arzobispo Basilio Tomás Sancho Hernando por permitir al provisor de indios y chinos de Manila hacerse llamar inquisidor de indios y presidir un tribunal denominado Santo Oficio y Tribunal Metropolitano de Fe de Indios e Isleños Filipinos, con autoridad para nombrar comisarios, notarios, familiares, consultores y calificadores. Este presunto tribunal tenía facultades para procesar herejías. ${ }^{17}$

Los conflictos y la desobediencia formaban parte de la vida eclesiástica quizá debido a la ausencia de una autoridad imponente. Ante esta situación, destaca el hecho de que las decisiones de la arquidiócesis de México no siempre se aplicaban o interesaban en la diócesis de Manila, a pesar de ser una administración sufragánea. Lo cierto es que la distancia impedía la comunicación efectiva. De ahí que hubiera necesidad de concederle autonomía a la prelatura filipina.

El asunto territorial constituía la complicación más urgente. La autonomía eclesiástica se alcanzaría en 1595, cuando Manila se convirtió en arquidiócesis, con tres diócesis sufragáneas que facilitaron la administración espiritual de la jurisdicción. En el extremo sur, se formó la diócesis de Cebú, en el norte, Nueva Segovia y en el este, Nueva Cáceres. La escisión del territorio, mediante la separación de las grandes islas y sus anexas, pretendía tener un control más efectivo de la población.

${ }^{16}$ Acerca de la desobediencia de los clérigos filipinos, véase García Garrido 2015.

${ }^{17}$ Archivo Histórico Nacional, Madrid [en adelante AHN], Inquisición, 2286, caja 1. 
Las nuevas diócesis sufragáneas no se convirtieron en comisarías diocesanas de forma automática. ${ }^{18}$ La primera división inquisitorial se estableció en 1600 con el nombramiento de fray Martín Zamudio como comisario del distrito de Cebú, también denominado Nombre de Jesús, con jurisdicción en las provincias de Iloílo, Bugasong, Cápiz, Cebú, Isla de Negros, Otón, Panay, Carbalogan, Caraga, Surigao y Calamianes, con una extensión de $160000 \mathrm{~km}^{2}$ y que comprendía las islas de Mindanao, Samar, Joló, Bisayas, Paragua, Calamianes y Marianas, con capital en el puerto de Cebú.

El gobierno de las dos comisarías diocesanas se repartió en los dos núcleos de población más importantes de las Filipinas, en el norte Manila y en el sur Cebú. Las dimensiones de la comisaría manilense, reducida a $140000 \mathrm{~km}^{2}$, tendría jurisdicción en las islas de Luzón, Mindoro, Masbate, Bulán y Catanduanes.

En los años siguientes, se establecieron dos nuevas comisarías en las fronteras diocesanas que pertenecían a la capital filipina. La elección de comisario de fray Lorenzo de León, en 1604, en un rosario de pueblos e islas centro-orientales de las provincias de Camarines, Ibalón, Leyte, Carigara, Catbalogan, Sorsogón, Tayábas y Santa Cruz de la Laguna en las islas de Luzón y Catanduanes, con una extensión de 40000 km², creaba la comisaría diocesana de Nueva Cáceres o Camarines, con capital en la ciudad de Cáceres.

El distrito de Nueva Segovia, también llamado Cagayán, se constituyó en 1606. En el título emitido a fray Pedro de Solier, se estableció que la jurisdicción, ${ }^{19}$ en el extremo septentrional de Luzón, incluía las provincias de Cagayán, Ilocos y Pangasinán, con una extensión de 55000 km². La sede del comisario fue capital homónima del obispado.

${ }^{18}$ La distribución de los pueblos por diócesis, provincias y curatos, año de fundación, habitantes y eclesiásticos puede verse en «Extracto pvntval con vn mapa distinguido y general del número de ministerios de las Islas diuidido por sus Obispados y prouincias», que forma parte del "Expediente sobre el número de religiosos de Filipinas», Archivo General de Indias [en adelante AGI], Filipinas, 324, N. 1.

${ }^{19}$ La distribución de pueblos y habitantes de las provincias del obispado de Nueva Segovia puede verse en «Expediente sobre provisión y visita de doctrinas» (1770), AGI, Filipinas, 303, n. 5, f. 526. 
La modificación de la geografía inquisitorial en los primeros años del siglo XVII transformó las fronteras originales del distrito manilense. Después de la división, la comisaría de Manila abarcaría las provincias de Tondo, Bulacán, Pampanga, Cavite, Laguna de Bay, Batangas, Mindoro, Mariveles y Zambales, ${ }^{20}$ con una extensión territorial de $45000 \mathrm{~km}^{2}$, en las islas de Luzón, Mindoro y Marinduque (Véase Cuadro I y Mapa I).

De este modo, la audiencia quedaba dividida en cuatro distritos inquisitoriales, con ejes centrales en las principales poblaciones españolas, y desde ahí se pretendía ejercer un control más efectivo sobre la población sujeta a la autoridad del Santo Oficio. La llamada visita de distrito constituyó una de las funciones más importantes de los comisarios diocesanos; sin embargo, la compleja orografía, el clima y las comunicaciones internas entre islas impidió su realización. De todas maneras, la mayoría de los hispanos habitó principalmente en las capitales eclesiásticas y lugares donde se ubicaron las comisarías dependientes. Las diócesis de Manila y Cebú registraban el mayor número de españoles, mientras que en Nueva Segovia y Nueva Cáceres, había muy pocos. Aun cuando hubo mestizos, sangleyes y moros en el territorio, en general, el Santo Oficio filipino no tenía demasiada preocupación por sus comportamientos y desviaciones.

Cuadro I. Comisarías diocesanas de la audiencia de Manila

\begin{tabular}{lrlrl}
\hline $\begin{array}{l}\text { Comisaría } \\
\text { diocesana }\end{array}$ & $\begin{array}{c}\text { Extensión } \\
\mathrm{km}^{2}\end{array}$ & Capital & Creación & Comisario \\
\hline Manila & 45000 & Manila & 1583 & Francisco Manrique \\
Cebú & 160000 & Cebú & 1600 & Martín de Zamudio \\
Nueva Cáceres & 40000 & Cáceres & 1604 & Lorenzo de León \\
Nueva Segovia & 55000 & Nueva Segovia & 1606 & Pedro de Solier \\
\hline
\end{tabular}

Fuente: Miranda Ojeda 2019: 158-159; Rodrigues Lourenço 2020.

${ }^{20}$ La distribución de pueblos y habitantes de las provincias del arzobispado de Manila puede verse en «Expediente sobre provisión y visita de doctrinas» (1770), AGI, Filipinas, 303 , n. 5 , f. 552. 
Mapa I. Comisarías diocesanas del Santo Oficio en la Audiencia de Filipinas

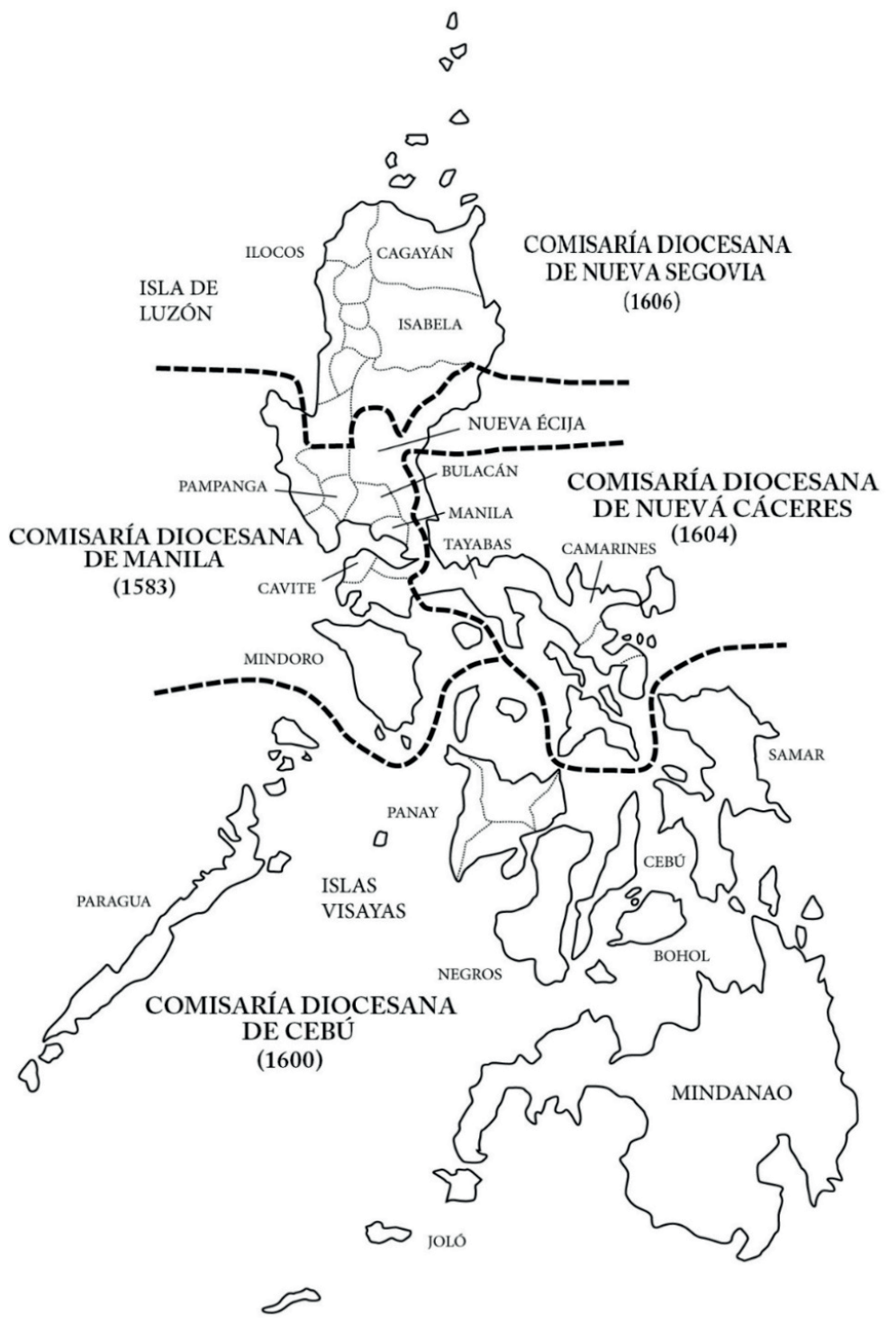

Fuente: Mapa elaborado a partir de Blanco Andrés 2018: 96. 


\section{LA DISRUPCIÓN DEL ORDEN ADMINISTRATIVO: LAS COMUNICACIONES} CON EL TRIBUNAL DE MÉXICO

La posición hegemónica del tribunal de México en la administración de las comisarías filipinas mediante correspondencia es lo que José Araneda Riquelme denomina gobierno de papel. ${ }^{21}$ Este concepto pretende explicar que los vínculos administrativos del gobierno son exclusivos de una sede central que controla, define políticas y regula la gestión local desde una posición de poder e intervención hacia sus satélites, constituyendo el único mecanismo de integración de los territorios inmersos en un proceso de centralización. Esto no quiere decir que la posición dominante sea de absoluto control, sino que la distancia geográfica incide para que también se desarrollen espacios de negociación y de adaptación.

Esta relación comunicativa define cómo se imbrican funcionalmente la administración y la información como forma de dominio. El dominio, por tanto, no constituye un organigrama de funciones asignadas, sino una formación de comunicación política, cuyo control se ejerce en aquellos lugares donde había representación de las instituciones. ${ }^{22}$ En el dominio de distancia, el ejercicio del poder se limitaba por distintas variables y, a menudo, era difícil que funcionara. En las esferas locales, era posible conseguir arreglos y dirimir los conflictos de intereses sin necesidad de comunicarlos a la Corona. ${ }^{23}$ De ahí que, en las periferias de los dominios españoles, la Audiencia de Filipinas constituyó una posesión cuya distancia superlativa incidió en su administración. La ubicación geográfica repercutió en la ralentización del régimen administrativo y en el intercambio de ideas, normas, consultas, resoluciones, etc. procedentes de Nueva España. La insubordinación y conflictividad, que caracterizaban a las élites locales, se explica por la toma de decisiones a menudo sin contar con licencia para ello. De ahí su insistencia en contar con autonomía en los asuntos más urgentes; sin embargo, la convocatoria para asumirla no siempre fue bien recibida por las autoridades virreinales. Si bien había

\footnotetext{
${ }^{21}$ Araneda Riquelme 2020: 17-18.

${ }^{22}$ Brendecke 2016: 486.

23 Ib.: 264.
} 
prosperado su independencia eclesiástica de México al convertirse en arquidiócesis, la situación no fue la misma cuando pretendieron lograr una autonomía inquisitorial.

La circulación de la correspondencia que estaba adscrita a la flota ultramarina describe una relación recíproca entre relaciones mercantiles y postales entre ambos lados del Mar del Sur. También define una relación hermética porque solo había un viaje anual. La inmensidad del Mar del Sur que separaba a las comisarías diocesanas filipinas con la sede del tribunal de Nueva España se convirtió en uno de los asuntos más complejos. El viaje y tornaviaje anual de la flota de Filipinas, con una duración de tres a cinco meses y de seis a ocho meses de travesía, respectivamente, a menudo estuvo subordinado a las condiciones climatológicas favorables que permitieran las travesías, sobre todo en el viaje que, además, por distintos motivos, podía retrasarse o suspenderse para evitar la pérdida de navíos.

En este sentido, las pérdidas no solo eran de vidas y navíos, sino también de documentación inquisitorial importante. ${ }^{24}$ En estas situaciones, por lo tanto, había incapacidad para poder articular el despacho de los pliegos que se perdían, lo que muestra la enorme fragilidad que existía en la administración y en la circulación de la correspondencia. En los registros, existen noticias de que en los $16000 \mathrm{~km}$ de la ruta Acapulco-Manila hubo hundimientos, naufragios o ataques piratas en los años 1601, 1639, 1649, 1654, 1655, 1743, 1751, 1771 y 1762, mientras que en la peligrosa travesía Manila-Acapulco hubo pérdidas de navíos por corrientes marítimas, tempestades, ataques piratas, naufragios e, incluso, por sobrepeso de los navíos, por lo menos, en los ańos 1587, 1590, 1595, 1600, 1603, 1609, 1610, 1629, 1631, 1656, 1692, 1693, 1694, 1708, 1709, 1726, 1732, 1743, 1750, 1753, 1762, 1775 y 1798. ${ }^{25}$ Además, en los años 1646-1648, 1682, 1686-1687 no se salió del puerto por las

\footnotetext{
${ }^{24}$ La pérdida de cajones de correspondencia que el tribunal limeño despachaba, desde el puerto de Callao, al Consejo de Inquisición también solía deberse a hundimientos, incendios y ataques piratas (Vassallo 2019: 62-64).

${ }^{25}$ Cadavid Arango 2020; Narrativa Histórica 2019; AGI, Filipinas, 193, N. 28; AGI, Filipinas, 22, R. 8, N. 36; AGI, Filipinas, 20, R. 4, N. 31; AGI, Filipinas, 332, L. 11.
} 
difíciles condiciones para realizar viajes. El jesuita Gregorio López, en 1607, a propósito de la pérdida de navíos afirmaba que:

Bien se deja a entender que estando estas islas tan distantes, no solamente de Europa sino de Nueva Espańa. Y siendo las navegaçiones tan prolijas y peligrosas, especialmente las de la buelta de aquí a Nueva España en que [se] han perdido tantas naos y personas, arribando después muchos días y meses de andar por la mar y quando an segido su camino como en stos dos años próximos de 605 y 606 ce ha [i]do a la mar çerca de çien personas cada vez, hasta venir a quedar sin gente que pudiese marchar. ${ }^{26}$

La transferencia de conocimientos a través de la correspondencia constituyó una forma de desplazamiento fáctico del poder para la toma de decisiones. El control del saber, por tanto, definió el orden de la legitimidad y la justicia del tribunal. ${ }^{27}$ En este sentido, la confiabilidad y funcionalidad de la correspondencia, mediante la transferencia gradual del saber en la documentación, garantizó la aplicación sistemática de los procedimientos. Ante esta situación, es importante recordar que todos los comisarios filipinos tenían la obligación de enviar al tribunal de México, en los navíos de la flota que partían una vez al año, los cajones de correspondencia — consultas, actividad procesal y demás trámites tocantes al Santo Oficio- ${ }^{28}$. De la misma manera, anualmente también debía recibirse la producción de documentos procedentes de la sede inquisitorial, los papeles de Manila, correspondencia enviada a Filipinas por el tribunal — consultas, resoluciones, órdenes, edictos de fe, nombramientos, etc. - destinada a las comisarías de los cuatro distritos inquisitoriales. ${ }^{29}$

${ }^{26}$ AGI, Filipinas, 79, N. 64.

27 Brendecke 2016: 304.

${ }^{28}$ Archivo General de la Nación, México [en adelante AGN], Inquisición, vol. 991, exp. 6. Está ampliamente documentado el envío de correspondencia de los tribunales de Indias al Consejo de Inquisición. Sobre los cajones de correspondencia que México enviaba desde Veracruz, véase AHN, libro 1068; AHN, 1741, n. 6; AHN, 2280; AHN, 2283. Sobre Lima véase Vassallo 2019: 62-63.

${ }^{29}$ AHN, Inquisición, Libro 5348, exp. 6; AGN, Inquisición, vol. 991, exp. 7; AGN, Inquisición, vol. 1151, exp. 3; AGN, Inquisición, vol. 1138, exp. 22. 
La situación de periferia de las comisarías filipinas también corresponde al modelo que Elizabeth Montañez denominó imperio de archipiélagos. ${ }^{30}$ Desde su perspectiva, este modelo se aplica cuando existen distintos centros de control y de periferia en interacción. En este sentido, México constituyó un centro que controlaba el vínculo con las comisarías filipinas y, al mismo tiempo, convertía a Manila en un centro de control al asumir una posición dominante de las restantes comisarías, puesto que en su responsabilidad de administrar la correspondencia también se arroga el conocimiento de información confidencial y reservada exclusivamente a los comisarios de cada una de las jurisdicciones. El control del conocimiento le permitió, por lo tanto, tener una posición privilegiada que pudo utilizar en su provecho respecto las decisiones transmitidas por el tribunal de México. Esto quiere decir que Manila no figuró como un simple distribuidor de correspondencia, sino que tiene un papel activo más preponderante en tanto controló las diferentes escalas de transmisión de información y movilidad de la correspondencia multidireccional a las comisarías. En esta medida, puede considerarse que el poder del comisario diocesano de la capital estuvo por encima de los restantes comisarios de la Audiencia de Filipinas.

La pérdida de los navíos o la suspensión de un viaje, por lo tanto, complicaban la administración eficiente. No obstante, el Santo Oficio tuvo como medida precautoria que, de la documentación generada y enviada al tribunal, principalmente los expedientes de causa procesal, se debía hacer una copia auténtica y, una vez confirmada su recepción, el original debía enviarse a los inquisidores de México. Esta práctica administrativa, que puede considerarse innecesaria, brindaba la seguridad de conservar siempre en custodia una copia, sin temor a perderse en los caminos o en los mares. Por obvias razones, hubo retrasos por el envío de nuevas comunicaciones y en las resoluciones de los inquisidores. Esto no quiere decir que todos los comisarios cumplieron con esta disposición y, por ello, en ocasiones, la pérdida de la documentación significaba la

${ }^{30}$ Araneda Riquelme 2020: 19. 
pérdida de los expedientes originales. De ahí que, en 1676, solo hubiera lectura de edicto de fe en Manila. ${ }^{31}$

También hay que tomar en consideración la difícil comunicación interna entre islas. Los desafíos geográficos y logísticos que implicó el traslado de mercancías, correspondencia y personas a menudo también provocaron múltiples pérdidas de navíos. ${ }^{32}$ En 1753, por ejemplo, el comisario de Manila, fray Bernardo de Ustáriz, manifestó que varios edictos de fe se habían publicado en Cavite e Ilocos y que, sin embargo, no pudieron leerse en Cebú porque se extraviaron en el camino, mientras que en las islas Marianas tampoco ocurrió porque no hubo navíos en esa dirección. ${ }^{33}$

No obstante, la lentitud en la transmisión de la información interna entre comisarías también puede arrogarse al comisario manilense. Una de las funciones más importantes en los puertos de mar consistió en abordar los navíos de entrada del ultramar antes del descenso de las mercancías y de los pasajeros. La identificación de la literatura prohibida y de sujetos sin los permisos correspondientes eran tareas medulares que el comisario debía efectuar para evitar la introducción de ideas subversivas y, principalmente, de judíos. A pesar de ello, la visita de los navíos fue una práctica que, a partir de 1690, tardó casi medio siglo en ejecutarse. El comisario de Manila fray Juan de Arrechedera justificó esta ausencia porque los comisarios no tenían una barca apropiada para poder acer-

${ }^{31}$ AGN, Inquisición, vol. 621, exp. 8.

32 Para la primera mitad del siglo XVII, por ejemplo, existen registros de pérdidas de navíos en navegaciones internas, por lo menos, en los años 1605, 1607, 1618 y 1638 (AGI, Filipinas, 19, R. 6, N. 91; AGI, Filipinas, 29, N. 90; AGI, Filipinas, 7, R.5, N. 53; AGI, Filipinas, 27, N. 235). Los peligrosos musulmanes de Mindanao a menudo realizaban incursiones y agredían a los españoles de las islas Pintadas hasta llegar a Mindoro, Manila y circunvecindades, capturando gente nueva en la fe y destruyendo pueblos e iglesias, «haciendo las navegaçiones de estas islas poco seguras» (AGI, Filipinas, 79, N. 64). Los musulmanes se encontraban en el sur, en la zona de Mindanao y Joló; los holandeses (calvinistas) se habían establecido en Molucas y Formosa; mientras que los ingleses (anglicanos) surcaban los mares realizando ataques piratas; además de distintos asiáticos que también practicaban la piratería (Ramírez Méndez y Espinosa Leal 2020: 163). Al respecto, véase también Descalzo Yuste 2015: 361-369.

${ }^{33}$ AGN, Inquisición, vol. 999, exp. 26. 
carse al muelle del puerto, no estar siempre ciertos de las fechas de las arribadas, monzones, etc. En 1737, el comisario adujo en su favor que cuando los navíos llegaron a Manila y Cavite, no solo estaba ausente de Manila, sino también había un monzón, mientras que el segundo comisario, fray Cristóbal Alonso, hallábase enfermo. De tal suerte que cuando tuvo conocimiento, las cargas ya habían sido depositadas en las bodegas y, obviamente, los pasajeros se habían diseminado en distintos puntos de las islas. ${ }^{34}$ Ante la gravedad del asunto, el Santo Oficio tomó medidas enérgicas para solucionarlo; y fue así que, en 1741, Arrechedera confirmó la reanudación de las visitas a los navíos en los puertos de Manila y de Cavite. ${ }^{35}$ No obstante, en 1753, el gobernador y capitán general de las islas Filipinas, el marqués José Francisco de Ovando, reiteraba a los inquisidores de México que todavía había dificultades para efectuar visitas regulares a todos los navíos, ya que el comisario no tenía una embarcación propia ni los recursos suficientes para sufragar los gastos necesarios de esta actividad. ${ }^{36}$

Por otra parte, el problema de comunicación del tribunal con las comisarías fue común en la misma Nueva España. El comisario de Nuevo México, fray Alonso de Benavides, solía quejarse de que el correo con frecuencia tardaba más de cuatro años, ${ }^{37}$ a pesar de que el viaje duraba seis meses en recorrer los $2560 \mathrm{~km}$ del Camino Real de Tierra Adentro. Las comisarías de los distritos inquisitoriales de Guatemala, Honduras y Nicaragua también adujeron los mismos argumentos:

Si la ciudad de Guathemala está a 300 leguas de México, Nicaragua más de 400, y las Philipinas 3.000, ansí no es posible poderse acortar tanto el arbitrio [...] a los comisarios como en España, donde la ciudad más distante de su Tribunal está poco más de veinte leguas, con las estafetas y correos ordinarios a la posta, que también faltan en las Indias. ${ }^{38}$

34 Pérez-Marchand 2005: 58.

${ }^{35}$ AGN, Inquisición, vol. 903, exp. 38; AGN, Inquisición, vol. 903, exp. 39.

36 Pérez-Marchand 2005: 58.

37 Alberro 1988: 24.

${ }^{38}$ AHN, Inquisición, Libro 1052. 
Sin embargo, el mayor inconveniente que retrasaba la actividad y perjudicaba el funcionamiento del tribunal era la inconmensurable tarea administrativa concentrada en dos inquisidores y un fiscal. Entre ellos, se repartían la compleja y extensa función burocrática, ralentizando los trámites y respuestas a las solicitudes, la actividad procesal, distintas comisiones y un largo etcétera de asuntos provenientes de distintas partes del extenso distrito inquisitorial. La responsabilidad de controlar el flujo informativo y la urgencia de las comunicaciones no siempre podían llevarse de manera expedita, sino que eran atendidas según fueran revisadas porque no había personal suficiente para realizar la tarea; de ahí que la lectura de la correspondencia se retrasara con mucha frecuencia mientras se cuidaban los asuntos cotidianos en el mismo tribunal. Por lo tanto, las respuestas a consultas, seguimiento de procesos, nombramientos, edictos de fe, etc. enviados a las comisarías podían tardar meses o años antes de resolverse y, en consecuencia, después, considerar el tiempo para retornar a su punto de origen. ${ }^{39}$ La situación más compleja correspondía a las comisarías filipinas. En primer lugar, el traslado de la correspondencia a Acapulco para entregarla al comisario ahí residente para el envío de los cajones. En segundo lugar, para aprovechar las corrientes marítimas y la orientación de los vientos, había que esperar la partida de los navíos, a más tardar en el mes de abril; mientras que de Manila debían salir en los primeros días de julio para llegar a puerto en diciembre, aunque algunos arribaron en noviembre o enero. ${ }^{40}$

El flujo de la comunicación determinada por las partidas de los navíos en ciertas fechas del año tenía incidencia en la respuesta expedita a la correspondencia. Esto quiere decir que la documentación generada en alguna comisaría filipina en el primer semestre del año tenía que trasladarse a Manila para esperar el mes de julio, cuando los cajones de correspondencia se enviaban a Acapulco y de ahí a México, donde había que esperar varios meses hasta que los inquisidores respondieran la solicitud y que esta coincidiera con el tornaviaje del mes de abril para

\footnotetext{
${ }^{39}$ Miranda Ojeda 2019: 171

${ }^{40}$ Cadavid Arango 2020: 80.
} 
su envío a Manila. De tal forma, que la contestación más inmediata de la correspondencia tenía que esperar por lo menos un año. Sin embargo, cuando el expediente iniciaba sus trámites en el segundo semestre del año, la espera era de casi un año antes de su envío al tribunal, tiempo que se incrementaba si el navío no salía de puerto o cuando este se perdía por distintas circunstancias, retrasando todavía más la correspondencia porque tendría que volver a enviarse.

La constante preocupación de los inquisidores de México por esta situación incidiría en el ajuste de sus comunicaciones. Por este motivo, la documentación destinada a Filipinas hubo que prepararse y anticiparse a potenciales eventualidades provocadas por las contingencias y a los tiempos de envío en los navíos. ${ }^{41}$ Mientras tanto, Filipinas pretendía fracturar la subordinación a México, estableciendo en Manila un tribunal del Santo Oficio que aliviara todos los escollos y problemas de dependencia administrativa.

\section{LOS INTENTOS DE CREACIÓN DE UN TRIBUNAL DEL SANTO OFICIO EN FILIPINAS}

La complejidad de la administración filipina, derivada de los desafíos geofísicos y logísticos de comunicación, se manifestaría en el funcionamiento de las comisarías y en el retraso de la actividad procesal. Por esta razón, hubo varios intentos por conseguir la autonomía mediante el establecimiento de un tribunal inquisitorial en las islas.

A escasos tres lustros de fundarse la primera comisaría diocesana, se registra la primera pretensión para constituir un tribunal. La propuesta se planteó en dos cartas, del recién electo primer arzobispo de Manila, fray Ignacio de Santibáńez, enviadas a Felipe II en 1598. En una carta, fechada el 24 de junio, expresaba su desazón por la pobreza de la catedral y solicitaba el establecimiento de un tribunal del Santo Oficio en la ciudad de Manila. ${ }^{42}$ En otra carta, fechada el 26 de junio, informa acerca de la necesidad de contrarrestar el poder del comisario diocesano,

\footnotetext{
${ }^{41}$ Rodrigues Lourenço 2019: 19.

${ }^{42}$ AGI, Filipinas, 79, N. 64.
} 
de las dificultades provocadas por la demora de la correspondencia y se manifestaba contra el envío de los procesos a México porque causaba gran desconcierto y era "manifiestamente injusto que los residentes de Filipinas sean juzgados por un tribunal extranjero", ${ }^{43}$ volviendo a insistir en la necesidad de establecer un tribunal en Manila.

En la segunda pretensión, fechada en Manila el 30 de julio de 1626, fray Pedro de Arce solicita a Felipe IV la creación de un tribunal en Manila. El obispo de la diócesis de Cebú, en una carta destacó la necesidad por "poner tribunal del Santo Officio en estas islas [...] porque aora todo lo tocante a éste va al tribunal Santo Officio de México». ${ }^{4}$ Como sucedió en 1598, ambas pretensiones fueron sobreseídas porque la carta no constituía el dispositivo jurídico que vindicara una solicitud de esta naturaleza ni transmite derechos ni obligaciones. ${ }^{45}$ La carta, instrumento de comunicación oficial más frecuente de las autoridades, tenía un carácter informal en que se procura la función notificativa, aun cuando a menudo aparecen cuestiones relevantes y de importancia político-administrativa. Por este motivo, la solicitud no estuvo sujeta a consulta ni tampoco recibió respuesta.

En términos administrativos, el memorial definía al documento jurídico destinado a la realización de solicitudes formales a la Corona. El origen del motivo iba acompańado de un vocabulario adecuado y con ciertas fórmulas legales que justificaban, con argumentos expositivos, el cumplimiento de una necesidad o de solucionar un problema determinado. En este sentido, sí constituía un instrumento jurídico vinculante con la solicitud y la autoridad tenía la obligación de responder. El primer memorial, fechado el 30 de junio de 1606, fue enviado al Consejo de Inquisición por el obispo de Nueva Segovia, fray Diego de Soria. En su exposición, solicita la instalación de un tribunal inquisitorial en las Filipinas debido a los muchos delitos cometidos en las islas en cuestiones tocantes al Santo Oficio que no pueden solucionarse de inmediato debido a la inconveniente ralentización de toda la actividad procesal

\footnotetext{
${ }^{43}$ Cunningham 1918: 420. Traducción propia.

${ }^{44}$ AGI, Filipinas, 76, N. 12.

${ }^{45}$ Real Díaz 1970: 270.
} 
que debe consultarse y votarse en México; de ahí que pretendiera que los inquisidores se nombraran de los muchos prohombres de las órdenes religiosas establecidas en las Filipinas. Desde su punto de vista, considera que «con esto se remediarán los daños, y no habrá costas, y obligación tienen los inquisidores de México a procurar esto por su parte». ${ }^{46}$ No obstante, aunque las consultas y toda la documentación no ha podido ser localizada, la solicitud fue rechazada.

La segunda iniciativa jurídica se realizaría a mediados del siglo XVII. Los inquisidores de México, reconociendo los graves problemas de comunicación que arrostraba la administración filipina, en 1655, habían propuesto al Consejo de Inquisición la fundación de un tribunal en Manila. La solicitud había comenzado a analizarse, solicitando informaciones adicionales, ${ }^{47}$ cuando el jesuita Francisco Vello, procurador general de las Filipinas, presentó una propuesta simultánea en Madrid, probablemente a fines de septiembre o principios de octubre de 1658, ante el Consejo de Inquisición y el Consejo de Indias. En los memoriales enviados a ambos consejos, consideraba que la distancia entre la sede del tribunal y las Filipinas ocasionaba enormes perjuicios al funcionamiento efectivo de la administración, principalmente por los enormes problemas de comunicación, por tiempo y costos; esta situación implicaba problemas en la trasferencia de documentación y de reos. Asimismo, también pretendía justificarse la formación de un tribunal aludiendo que en las Canarias había un tribunal, dado que estaba a una distancia de doscientas leguas de España. Por último, enfatiza que la instalación del tribunal en Manila no se traduciría en gastos para la Real Hacienda, sino que pretendía el incremento de los tributos de los indios. ${ }^{48}$ Las consultas realizadas a las autoridades de México y de las Filipinas acerca de la conveniencia de constituir el tribunal observan la disposición positiva por cumplir con la vieja demanda que incluso el Santo Oficio de México había promovido; sin embargo, la solicitud fue rechazada. La respuesta quizá se explique porque se consideraba que las

\footnotetext{
${ }^{46}$ Medina 1899: 36-38.

${ }^{47}$ Rodrigues Lourenço 2019: 39.

48 Sales Colín 2000: 266-267; Rodrigues Lourenço 2019.
} 
Filipinas no tenían los recursos suficientes para afrontar los gastos de sostenimiento de un tribunal y, principalmente, el fortalecimiento del poder del clero regular filipino. ${ }^{49}$ Ante el desconocimiento de las discusiones finales, puede considerarse que la concesión del poder inquisitorial a las órdenes religiosas dominantes haya sido la causa determinante del rechazo a establecer el tribunal, toda vez que ello podría significar la eclosión de complejas relaciones políticas, difíciles de controlar por las autoridades políticas filipinas y por la misma Corona, en virtud de que durante años las órdenes se había distinguido por su desobediencia e insumisión a las autoridades.

La última iniciativa se presentó a mediados del siglo XVIII. Francisco de Rauzo presentó en Madrid, en 1749, un extenso memorial. En primer lugar, destacó la importancia política y eclesiástica de las islas, toda vez que ahí había gobernador y capitán general, audiencia, contaduría, además de que un arzobispado, cabildo catedralicio, dos universidades, seminario, etc. En segundo lugar, manifiesta que, por las actividades comerciales, concurrían ahí gente de India Oriental, Tartaria, Armenia, Europa, China, Japón y Mogol, muchas conocidas como naciones idólatras, musulmanas y herejes, por lo cual era necesario defender la fe católica. En este sentido, considera necesario establecer un tribunal del Santo Oficio en las Filipinas. En su exposición, introduce uno de los más graves inconvenientes de la dependencia de la comisaría diocesana de Manila con México, la enorme distancia que había ocasionado numerosos problemas de comunicación. Aun cuando considera importante formar nuevas comisarías en las provincias más extensas, reconoce que las dificultades serían las mismas dado que los «comisarios separados, no formando un cuerpo o tribunal, y careciendo de ministros para poder inquirir y formar causas con el acierto que acostumbra el Santo Oficio». ${ }^{50}$ En este punto, Rauzo advierte acerca del enorme poder de los comisarios diocesanos que tienen facultades extraordinarias. En el memorial, insiste en la comisaría como una instancia donde «viene a depender de

${ }^{49}$ Sales Colín 2000: 268.

${ }^{50}$ Medina 1899: 142-145. 
un hombre solo la formación de causas del mayor momento, y pidiendo éstas muchas veces una pronta resolución, como la prisión, etc. o la habrá de determinar un hombre solo, tan expuesto a errar». ${ }^{51}$ De ahí su insistencia en que el gobierno inquisitorial de un territorio tan extenso no podía estar en posesión exclusiva de los comisarios, a la vez que insiste en la complejidad de las comunicaciones ultramarinas, la pérdida de la correspondencia y la ralentización de los procesos que debían votarse en México. ${ }^{52}$

Por otra parte, señala que la integración del tribunal se hiciera a propuesta del arzobispo de Manila. La elección de los distintos funcionarios se consideraría de los muchos eclesiásticos beneméritos de la Iglesia, inclusive entre las órdenes habidas en las islas. ${ }^{53}$ Para remediar la constante ausencia de ministros que no podían sustituirse de manera inmediata por la tardanza de los nombramientos desde México, propuso la nominación de tres sujetos de la misma orden en un sistema de sustituciones que garantizara la continuidad funcional. ${ }^{54}$

Desde su punto de vista, Rauzo consideró cinco elementos fundamentales para establecer un tribunal inquisitorial en Manila: 1) La presencia de gentiles, herejes, musulmanes, cismáticos y cristianos dedicados al tráfico mercantil representaba un peligro inminente de contaminación

${ }^{51}$ Medina 1899: 145. Se refiere al proceso inquisitorial incoado en 1668 y que terminó con la muerte del gobernador Diego de Salcedo en 1669. Aun cuando detrás de la denuncia hubo intrigas políticas e intereses económicos, la enemistad del comisario Joseph de Paternina y Samaniego fue clave en la conspiración de una parte de las élites filipinas contra Salcedo. De ahí que, sin la autorización de México para proceder con su aprehensión, consideró que había elementos suficientes que indicaban su presunta huida. Por lo tanto, ordenó su detención para procesarlo por tratar con herejes, evitar la confesión, vivir amancebado con una mujer casada, decir palabras contra el Santo Oficio y afirmar que la cristiandad aseguraba la salvación. Durante su traslado a Nueva España, murió en la inmensidad del Mar del Sur. Ante la compleja situación, devino una disputa de jurisdicciones y la intervención del Consejo de Inquisición que, en 1671, decretó la ilegitimidad del proceso y la suspensión del embargo de bienes. También destituyó de sus funciones al comisario Paternina (Picazo Muntaner 2013: 381-384; Medina 1899: 83-130).

52 Medina 1899: 145.

53 Ib.: 148.

${ }^{54}$ Ib.: 148-149. 
espiritual; 2) la ausencia de comisarios en muchos lugares; 3) las costumbres de comerciantes extranjeros ajenos y desconocidos sobre las que los inquisidores de México debían consultar a los teólogos acerca de su cristiandad; 4) la cercanía de las misiones de la Congregación de Propaganda Fide, aunque ausentes de las Filipinas, era una amenaza que solo un tribunal puede contrarrestar, y 5) los jansenistas, en regiones cercanas, constituían una razón suficiente para enfrentar la herejía y formar un tribunal. ${ }^{55}$

Las autoridades actuaron en consecuencia del memorial. No obstante, las consultas y demás documentación están extraviadas. La solicitud enviada al procurador de las Filipinas para que propusiera un informe financiero, buscando garantizar el establecimiento del tribunal y asegurar su funcionamiento, puede interpretarse como la primera iniciativa de procedencia para la fundación del tribunal. En su informe, el jesuita Pedro de San Cristóbal consideró que los ingresos podían provenir de tres rubros: primero, concederle la propiedad del empleo de secretario del gobernador - siempre vaco, dado en interinato, por no poder venderse el oficio- proporcionaría unos seis mil pesos; segundo, también la concesión de la secretaría de la ciudad, sustituyéndolo por un teniente, obtendría un poco menos, sin indicar la cantidad; $y$, tercera, concederle el estanco del buyo contribuiría con una renta de ocho mil pesos anuales. ${ }^{56}$ De cierta manera, la inconsistencia de la propuesta del jesuita incidiría negativamente en la decisión de fundar el tribunal en Manila. No solo proponía la obtención de recursos afectando otros intereses que quizá las autoridades políticas de las Filipinas no estaban dispuestas a aceptar, sino que, además, los recursos de la secretaría del gobernador no existían. De ahí que las pretensiones por contar con un tribunal se desvanecieran y no volviera a presentarse otra solicitud.

La dependencia de las comisarías de la Audiencia de Filipinas ante el Santo Oficio de México continuaría vigente. La compleja relación e inconvenientes derivados de la distancia no lograría solucionarse.

55 Ib.: 146-147.

56 Ib.: 150-151. 
Sin embargo, desde el temprano siglo XVII, mediante tres medidas ya se había procurado solucionar algunos de los mayores problemas: poderes de aplicación de sentencia, redefinición de jurisdicciones inquisitoriales e introducción de los comisarios de primer, segundo y tercer lugar.

\section{LA CONCESIÓN DE PODERES DE APLICACIÓN DE SENTENCIA A MANILA}

La primera medida introducida por los inquisidores de México para resolver el problema de la continuidad en la interlocución fue conceder a Manila poderes especiales. Esta medida se propuso ante las numerosas quejas derivadas de la ralentización de la correspondencia simultánea que, en consecuencia, afectaba la actividad procesal.

El 8 de mayo de 1611, el Santo Oficio de México solicitó al Consejo de Inquisición cambios en la aplicación de las sentencias de los procesos originados en las comisarías filipinas. Ante la tardanza de los procesos por las distancias y complejidad de trasladar a los reos procesados, propusieron el trasporte a Nueva Espańa de los reos con delitos mayores, mientras que aquellos cuya transgresión fuera considerada leve y sentencias menores — cárcel, azotes, abjuración, reconciliación, reclusión en convento, imposición de sambenito- - «el castigo y demostracion que en estos casos se suele hacer, sería muy más á propósito y conveniente que se hiciese allá donde se cometió el delicto, para ejemplo de los demás». ${ }^{57} \mathrm{El}$ 28 de noviembre de 1612, el Consejo de Inquisición decretó que las penas menores podían aplicarse en Manila. ${ }^{58}$ Las ventajas de esta modalidad punitiva no solo evitaba los largos procesos que comprometían el desplazamiento de los reos a México y el periodo de espera de las audiencias, que podían tardar varios meses antes de las sentencias, sino que los costos también se reducían considerablemente, tanto para el tribunal como para el inculpado. Hay que recordar que la responsabilidad financiera del sustento diario no estaba a cargo del Santo Oficio, sino de los reos. No obstante, la aplicación de estas medidas significó que la procuración de testimonios de los comisarios debía ser prolija y con suficientes elementos

${ }^{57}$ Ib.: 39 .

${ }^{58} \mathrm{Ib}$. 
para evitar dudas sobre la culpabilidad de los acusados. Una vez tomada la decisión, los inquisidores enviaban la sentencia que debía ejecutarse en Manila. Asimismo, como el Santo Oficio no tenía prisiones en las Filipinas, se decidió reducir las penas de prisión, excarcelándolos, una vez sustanciado y concluido el proceso.

Las sentencias, en efecto, se aplicarían en Manila. En 1620, por ejemplo, en una carta se confirma que "por lo tocante a la Inquisición [...] en las últimas naos nos remitió el comisario de Manila más testificaciones [...] y las reconciliaciones que hizo de algunos de estos hombres, que se delataron ante él espontáneamente». ${ }^{59}$ La continuidad de la práctica también puede advertirse en 1666, aun cuando los inquisidores reconocen que la blasfemia de los soldados era cosa común y, por lo tanto, necesario su traslado a México para su castigo. No obstante, en consideración a que la pobreza de los reos condicionaba la procuración de elevados gastos derivados del traslado, determinaron que "el comisario de la ciudad de Manila castigue y actúe, según estilo del Santo Oficio, [a] los blasfemos que fueren testificados y determine sus causas, o dispondrá la forma que fuere servido». ${ }^{60}$

Esta medida, sin embargo, no significó que la sentencia de mayoría de los presos se haya aplicado en Manila. En los autos de fe de México hubo numerosos reos procedentes de las Filipinas. La decisión acerca de quiénes permanecían en Filipinas y quiénes se desplazaban a México siempre fue de los inquisidores. Tampoco quiere decir que los delitos considerados leves siempre hayan conservado su carácter doméstico; en los autos de fe también se observa la sentencia de reos con este tipo de acusaciones. La importancia de esta medida radica en el reconocimiento que México concede a Manila para darle cierta autonomía en algunos asuntos. Sin embargo, puede considerase que, logísticamente, responden a una realidad que no podía obviarse ni justificarse en la estructura y en la complejidad situacional de la periferia. De este modo, se solucionaba el traslado de los reos procesados en las Filipinas, puesto que había

\footnotetext{
${ }^{59}$ Ib.: 49.

${ }^{60}$ Ib.: $53-54$.
} 
delitos cuyas sentencias podían aplicarse en el lugar de la transgresión. Es una concesión extraordinaria que no se aplicaría en ningún distrito novohispano, incluida Guatemala que, en varias ocasiones (1611, 1754 y 1766), también pretendió un tribunal en la Audiencia de Guatemala.

\section{LA REDEFINICIÓN DE LAS JURISDICCIONES: LAS COMISARÍAS DEPENDIENTES}

La segunda medida fue la introducción de las comisarías dependientes. La conformación de las cuatro comisarías diocesanas, con jurisdicción en sus respectivos territorios episcopales, no significó la definición última de las fronteras distritales, sino que por la experiencia novohispana se consideró necesaria una división interna. En los enormes distritos de las comisarías diocesanas establecidas en el continente, los inquisidores habían advertido desde el siglo XVI que los comisarios no tenían la capacidad para poder realizar las visitas de distrito debido a la complejidad geográfica. ${ }^{61}$

El archipiélago de las Filipinas está constituido por una miríada de 7100 islas de origen volcánico, de las cuales únicamente estaban pobladas unas 60, con más de $32000 \mathrm{~km}$ de costas de mar, lo que originaba un complejo laberinto de islas, islotes, canales y peñascos, con mares interiores profundos que convertían las visitas en tareas muy difíciles. La mayoría de las islas, con relieve accidentado y montañoso, son atravesadas por ríos de caudal diferente, y tienen clima tropical cálido y húmedo, con abundantes lluvias y espesas selvas tropicales.

Ante estas dificultades, la conquista española nunca alcanzó la totalidad de las islas ni un dominio colonial efectivo. Asimismo, en el archipiélago había pocos caminos, cuyas pésimas condiciones limitaban el empleo de cabalgaduras y obligaba a andar a pie distancias considerables. El itinerario terrestre se complicaba debido al calor y humedad extremos, además del cansancio físico, la incomodidad y las constantes lluvias, los moscos y los peligros naturales de las selvas. La insularidad determinó

${ }^{61}$ La complejidad geográfica y demográfica de las Filipinas puede verse en Vázquez de Espinosa 1948: 248-257. 
que la mayoría de los desplazamientos se hiciera por agua: por mar de una isla a otra y, a veces, de una parte, a otra de la misma isla; los ríos también se aprovecharon para transportarse desde la costa al interior y viceversa. Los problemas logísticos para realizar las visitas de distrito no solo implicaron la contratación de una embarcación y de su tripulación, sino también la compra de provisiones para un periodo de tiempo determinado. ${ }^{62}$ Los viajes marítimos solían ser peligrosos porque los rudimentarios navíos, pequeńos para maniobrarlos entre islas, bajos y estrechos canales, no siempre podían controlarse ante la fuerza de las corrientes. La intensidad del oleaje y la turbulencia de los mares a menudo eran una grave amenaza cuando las embarcaciones se desplazaban hacia los peńascos y arrecifes, ocasionando que terminaran encalladas en los bajos de las playas. ${ }^{63}$

Ante este difícil escenario, la solución fue incorporar nuevas jurisdicciones. Las comisarías dependientes, estructuradas en los límites diocesanos, creaban un mecanismo de división y reparto en villas, puertos de mar o ciudades, distribuidas en los lugares con la mayor población española en los distritos, para que ahí hubiera una representación del Santo Oficio. De este modo, se pretendía incorporar a numerosos comisarios dependientes autorizados para que representen al comisario diocesano en una jurisdicción, puesto que este personificaba a los inquisidores. La concesión de representaciones es inequívoca, porque los auténticos representantes del Santo Oficio son los inquisidores de México que, ante la dificultad de controlar la jurisdicción, distribuyeron concesiones a los comisarios diocesanos para que los representen y, estos a su vez, en su jurisdicción, concedieron su representación a los comisarios dependientes en determinados lugares del distrito. Aquellos lugares sin representación alguna, independientemente de la cercanía de un comisario dependiente, constituían parte de la jurisdicción diocesana.

La división de las comisarías diocesanas, sin embargo, no fue inmediata. Ya en 1652 se reconocía que, ante la numerosa población española y de

${ }^{62}$ Descalzo Yuste 2015: 270-271.

${ }^{63}$ Ib.: 358, 360-361. 
otras naciones, era necesario el establecimiento de nuevas comisarías, porque las provincias eran remotas y muy grandes. ${ }^{64}$ Ante el despliegue de comisarios en muchos lugares de la geografía filipina, un eclesiástico insistía, en 1659, en que había muchos comisarios incluso «donde no hay vezindad de españoles [...] se podía escusar el señalar españoles, que ya por muchos son poco estimados». ${ }^{65}$ Aun cuando en la comisaría diocesana de Nueva Cáceres solo hubo representación en la capital eclesiástica, en las jurisdicciones de Nueva Segovia, Manila y Cebú hubo comisarías dependientes durante los siglos XVII y XVIII (véase Cuadro II).

En la primera mitad del siglo XVII, comenzaría el proceso de reconfiguración del espacio inquisitorial filipino. Las primeras comisarías dependientes se establecieron en las jurisdicciones con población española más importantes. En el distrito de Manila se fundarían las comisarías de Pampanga (1616), Santo Domingo (1621), Mindoro (1626) y Cavite (1642). En la década siguiente, continuaría el proceso de distribución de comisarías en Terrenate (1654) y Tágalos (1669). Aquí es necesario analizar la situación del presidio Terrenate que, por su ubicación geográfica en el extremo marítimo meridional del archipiélago filipino, pertenecía a las islas Molucas y a Manila en su jurisdicción eclesiástica. La distancia de trescientas leguas y quince días de viaje a Manila complicaba su administración desde la capital y, dada su compleja jurisdicción y conflictos por su posesión, ahí fue necesario establecer una comisaría.

${ }^{64}$ AGN, Inquisición, vol. 442, exp. 22.

${ }^{65}$ Informe del padre Magino Solá a Diego de Arce y Reinoso, inquisidor general de España, citado por Rodrigues Lourenço 2019: 45. 


\section{Cuadro II. Comisarías fundadas en la Audiencia de Filipinas, siglos XVI-XVIII}

\begin{tabular}{|c|c|c|c|c|}
\hline $\begin{array}{l}\text { Comisaría } \\
\text { diocesana }\end{array}$ & $\begin{array}{c}\text { Extensión } \\
\mathrm{km}^{2}\end{array}$ & $\begin{array}{l}\text { Funda- } \\
\text { ción }\end{array}$ & Comisaría dependiente & Comisario \\
\hline \multirow[t]{10}{*}{ MANILA } & 45,000 & 1583 & MANILA & Francisco Manrique \\
\hline & & 1619 & Provincia de Pampanga & Martín de Agurto \\
\hline & & 1621 & Partido de Santo Domingo & \\
\hline & & 1626 & Provincia de Mindoro & \\
\hline & & 1642 & Puerto de Cavite & Diego de Bobadilla \\
\hline & & 1654 & Presidio de Terrenate & \\
\hline & & 1669 & Provincia de Tágalos & Luis de Montúfar \\
\hline & & 1701 & Provincia de San Gregorio & \\
\hline & & 1750 & Pueblo de Dilao & José de la Virgen \\
\hline & & 1750 & Misiones de Paniqui e Ituy & Vicente de Salazar \\
\hline \multirow[t]{11}{*}{ CEBÚ } & 160,000 & 1600 & CEBÚ & Martín de Zamudio \\
\hline & & 1636 & Villa de Arévalo & Lázaro Vázquez \\
\hline & & 1641 & Provincia de Mindanao & Francisco Colín \\
\hline & & 1652 & Puerto de Panay & Juan Lozano \\
\hline & & 1652 & Provincia de Caraga & Jacinto de San Fulgencio \\
\hline & & 1652 & $\begin{array}{l}\text { Provincias de Cuyo y } \\
\text { Calamianes }\end{array}$ & Joseph de la Anunciación \\
\hline & & 1656 & Provincia de Bisayas & Jerónimo de la Serna \\
\hline & & 1682 & Islas Marianas & Manuel Solórzano \\
\hline & & 1746 & Isla de Negros & Eugenio de Santacruz \\
\hline & & 1773 & Provincia de Iloílo & \\
\hline & & 1761 & Presidio de Zamboanga & Ignacio Mata \\
\hline $\begin{array}{l}\text { NUEVA } \\
\text { CÁCERES }\end{array}$ & 40,000 & 1604 & CÁCERES & Lorenzo de León \\
\hline \multirow{4}{*}{$\begin{array}{l}\text { NUEVA } \\
\text { SEGOVIA }\end{array}$} & 55,000 & 1606 & NUEVA SEGOVIA & Pedro de Solier \\
\hline & & 1652 & Provincia de Ilocos & Juan de Isla \\
\hline & & 1652 & Provincia de Cagayán & Carlos Clemente de Gan \\
\hline & & 1656 & Provincia de Pangasinán & Salvador Mejía \\
\hline
\end{tabular}

Fuentes: Miranda Ojeda 2019: 158-159; Rodrigues Lourenço 2020. 
Durante el siglo XVIII, se terminaría de delimitar el territorio con la incorporación de las comisarías de Dilao (1750) y Paniqui e Ituy (1750). Es importante mencionar que la comisaría de la provincia de San Gregorio (1701) constituyó una jurisdicción entonces desconocida en la tipología inquisitorial. La concesión del título de comisario al sacristán del convento de San Gil creaba la jurisdicción de la provincia franciscana de San Gregorio (1701). Esto no significaba la competencia jurisdiccional en un territorio no definido, sino que incorporaba a la provincia eclesiástica como una corporación territorial articulada un conjunto de casas organizadas y sujetas de un superior que residía en el convento matriz de Manila. Esto quiere decir que la jurisdicción abarcó todos los conventos franciscanos sin que implicara cercanía espacial ni una colindancia territorial definida, puesto que estaba dispersa en la Audiencia de Filipinas. La comisaría del Santo Oficio, sin embargo, no quedaba bajo autoridad del provincial, sino del comisario en turno que podría realizar trámites inquisitoriales exclusivamente sobre dichos conventos para «asegurar a los sugetos a dar parte al Santo Tribunal de México como ordinariamente a sido», muy distinta a su pretendida intención de adquirir jurisdicción sobre China, Japón y Maluco. ${ }^{66}$

En el distrito inquisitorial de Cebú, los primeros cambios se advertirían con la constitución de la comisaría en Arévalo, en la isla de Panay (1636). Sin embargo, también era necesario controlar lugares por su posición estratégica y dominados por musulmanes. En efecto, la provincia de Mindanao (1641) respondía a este modelo de comisaría que, además, tenía un extenso territorio,

en las islas de Zamboanga, Mindanao y Joló hay neçesidad de tener persona que haga officio de comisario de este Santo Officio, por ser partes habitadas de muchos géneros de naçiones y assistidas de españoles, soldados y mercaderes en sus presidios y poblaçiones y que acudan a las causas que se ofrecieren y perteneçieren tocantes a este tribunal. ${ }^{67}$

${ }^{66}$ AHN, Inquisición, 2273.

${ }^{67}$ AGN, Inquisición, vol. 416, exp. 8, f. 190. 
La enorme comisaría de Cebú, después de la escisión de Mindanao, comenzaría a descomponerse en comisarías más pequeñas. Los cambios se introducirían "por aber en dichas poblaçiones muchas gentes de todos estados y condiçiones, v.g. españoles, negros, mulatos y mestiços $y$ ofreçerze en ellos diferentes cossas y casos tocantes al tribunal de este Santo Officio». ${ }^{68}$ Ante la extensión de las islas Bisayas "por no haber comisario en las provincias muy dilatadas y poblados de Vissayas», ${ }^{69}$ se establecieron comisarías en Panay (1652), Cuyo y Calamianes (1652), Bisayas (1656) y, un siglo después, en Isla de Negros (1746). También se redefinieron las fronteras de Mindanao con la fundación de las comisarías de Caraga (1652), Zamboanga (1761) e Iloílo (1773).

La jurisdicción de las distantes islas Marianas (1682) merece revisarse por su peculiaridad. Las islas de Rota y Guaján, a cincuenta kilómetros de distancia entre ambas, eran las únicas que pertenecían a la Corona española. El puerto de San Ignacio de Agaña, en Guaján, tenía una enorme importancia estratégica y geopolítica gracias a su ubicación ultramarina en el viaje de la flota Acapulco-Manila, que servía de escala para el abasto y avituallamiento de navíos. No obstante, la ausencia de una comunicación directa con el tribunal complejizó su posición, ya que el comisario debía enviar su correspondencia vía Manila. A diferencia de otras comisarías, el trámite del correo de esta jurisdicción tenía características y tiempos distintos, porque Manila concentraba el nodo de comunicaciones con México. La dinámica de circulación de la información tenía dos implicaciones importantes. Por un lado, la ventaja de entregar sus cajones a la flota de tornaviaje a Manila y, por otro, la desventaja de que la navegación hacia Agaña era poco frecuente. Las corrientes marítimas de una ruta de poco más de $2500 \mathrm{~km}$ no siempre eran favorables, pues reducían el flujo mercantil a una embarcación anual y, por lo tanto, a menudo los comisarios no recibían la documentación inquisitorial. De ahí que el comisario fray José Bonarri manifestara en 1752 que durante nueve años no había tenido ninguna comunicación del

${ }^{68}$ AHN, Inquisición, Libro 1738, exp. 2, f. 186.

${ }^{69}$ AGN, Inquisición, vol. 442, exp. 23. 
tribunal. ${ }^{70} \mathrm{Al}$ año siguiente, como se ha mencionado con anterioridad, el comisario de Manila señaló que no podía enviar los edictos de fe a las islas Marianas, porque no había ningún navío en esa ruta. ${ }^{71}$ Esta situación también puede explicarse por la ausencia de trámites administrativos y de la actividad procesal. ${ }^{72}$ La mayor parte de la documentación de esta comisaría fueron nombramientos del Santo Oficio.

Por su parte, en el distrito de Nueva Segovia, los cambios ocurrieron a mediados del siglo XVII. La formación de las comisarías en sus tres provincias: Ilocos (1652), Cagayán (1652) y Pangasinán (1656) constituyeron la definición del control ejercido en una jurisdicción sin los problemas de la dispersión hispana en diferentes islas.

A pesar de los cambios jurisdiccionales introducidos principalmente desde mediados del siglo XVII, los resultados no siempre fueron satisfactorios. El tribunal de México reconocía la absoluta necesidad de que los comisarios asumieran un verdadero compromiso en sus funciones porque había muchos comisarios de nombre que no estaban cumpliendo con sus responsabilidades y, por lo tanto, hizo cambios en los nombramientos. En la comisaría de la provincia de Caraga, por sus muchas ausencias, fray Jacinto de San Fulgencio fue reemplazado por fray Juan de San Antonio, ambos agustinos. En las provincias de Cuyo y Calamianes, el comisario fray Joseph de la Anunciación no satisfacía sus funciones y, por sus ausencias, también fue sustituido por fray Salvador del Espíritu Santo, ambos agustinos. Por su parte, las ausencias del padre jesuita Juan López, comisario del puerto de Cavite, incidieron en el nombramiento de fray Ignacio de Muxica y Buitrón. ${ }^{73}$ Los dos comisarios de primer y segundo lugar del distrito de Manila fueron cambiados, ante sus omisiones de oficio frecuentes, por el dominico fray Francisco de la Trinidad por fray Juan Mallén de Loyola; mientras que fray Theodoro de la Madre de Dios reemplazó al anciano fray Carlos Clemente Gan. En Nueva Segovia, en cambio, las ausencias del mismo Gan — que, paradójicamente, figuraba

${ }^{70}$ AGN, Inquisición, vol. 999, exp. 20.

${ }^{71}$ AGN, Inquisición, vol. 999, exp. 26.

${ }^{72}$ AGN, Inquisición, vol. 650, exp. 2; AGN, Inquisición, vol. 1138, exp. 22.

${ }^{73}$ AGN, Inquisición, vol. 442, exp. 22. 
como comisario ausente en Manila y en Nueva Segovia - se solucionó con el nombramiento de fray Jerónimo de Zamora y, en su falta, fray Jacinto Gali, ambos dominicos. ${ }^{74}$

La ausencia de comisarios, por la tardanza de los nombramientos, configuraría un nuevo orden administrativo. Aun cuando desde el siglo XVII hubo intentos de solucionar esta situación, sería hasta la segunda mitad del siglo XVIII cuando comenzaría a aplicarse un sistema de sustitución de comisarios más efectivo.

\section{LOS COMISARIOS DE PRIMER, SEGUNDO Y TERCER LUGAR}

La tercera medida ejercida fue una respuesta a la lentitud de las noticias que afectaba no solo la actividad procesal, sino también la provisión de oficios. Los comisarios no siempre podían reemplazarse de inmediato debido a los retrasos de los correos, propiciando a menudo que los aspirantes asumieran sus funciones, en calidad de sustitutos no reconocidos por el Santo Oficio, antes de recibir sus respectivos nombramientos.

Una fórmula prístina había sido utilizada por los inquisidores desde mediados del siglo XVII. Ante las dificultades para resolver el problema de la sustitución inmediata de los comisarios, se emplearía el título de comisarios en segundo lugar. Uno de los primeros nombramientos de esta naturaleza data de 1641, cuando el franciscano fray Antonio de San Gregorio recibió el título de comisario «en la prouinsia de Camarines en segundo lugar». ${ }^{75}$ En su elección, el agustino fray Joseph de Paternina y Samaniego, en 1661, aparece como comisario en segundo lugar, mientras que fray Francisco de Paula tenía el nombramiento de comisario del Santo Oficio. ${ }^{76}$ La figura del comisario primero y segundo también aparece representada en Manila en esta época, sin una datación exacta, aunque ya en 1652 fray Francisco de la Trinidad y fray Carlos Clemente de Gan eran poseedores de dichos nombramientos y que, ante sus ausencias,

\footnotetext{
${ }^{74}$ AGN, Inquisición, vol. 442, exp. 23.

75 Rodrigues Lourenço 2020.

${ }^{76} \mathrm{Ib}$.
} 
fueron sustituidos por fray Juan Mallén de Loyola y fray Theodoro de la Madre de Dios, respectivamente. ${ }^{77}$

La compleja sustitución de los comisarios obligó a México a implantar de forma definitiva la representación de los comisarios en primer y segundo lugar. El comisario de Cagayán, fray Carlos Clemente de Gan, que, como se ha mencionado, paradójicamente también tenía el nombramiento de comisario segundo en Manila; pero ante sus constantes ausencias y su senilidad, fue reemplazado por fray Jerónimo de Zamora y fray Jacinto Gali, en primer y segundo lugar en orden de prelación. En la comisaría del puerto de Panay, desde el nombramiento del primer comisario, se estableció el estatus de dos comisarios, primero y segundo, en la representación de los agustinos fray Alonso Quijano y, a su falta, fray Juan Lozano. No sucedió lo mismo cuando se fundó la comisaría de la provincia de Ilocos, cuyo nombramiento se concedió exclusivamente a fray Juan de Isla. ${ }^{78}$ Esto quiere decir que solo existía la figura del comisario en segundo lugar, que tiene la función de sustituir temporalmente al titular en caso de ausencias o enfermedades y, en caso de renuncia, defunción o cambio de residencia, convertirse en comisario titular.

En el último tercio del siglo XVII, hubo cambios en el sistema de nombramientos manilenses. La inesperada muerte del comisario fray Diego de San Román, el 23 de diciembre de 1677, mientras realizaba una visita en Nueva Segovia, expuso que el sistema de comisarios de primero y segundo lugar no cumplía con su propósito. La ausencia de los comisarios sustitutos para encargarse de las responsabilidades inquisitoriales impulsó a los inquisidores de México a la confección de un nuevo sistema, más efectivo, que evitara que plazas importantes quedaran sin representante inquisitorial durante mucho tiempo.

La solución se firmó el 3 de marzo y se despachó el 14 de marzo de 1679. La respuesta consistió en el nombramiento de fray Baltazar de Santa Cruz como comisario en primer lugar, fray Bartolomé de Marrón, en segundo y fray Juan de Paz, en tercero. La orden se recibiría en Manila

77 AGN, Inquisición, vol. 442, exp. 23.

${ }^{78}$ AGN, Inquisición, vol. 442, exp. 23. 
a finales de año, dos años después de la muerte del comisario. ${ }^{79}$ En este marco, se inició la ejecución de los nombramientos otorgados para suplencia por causas de accidente, muerte o causa mayor en una provincia considerada altamente peligrosa. No obstante, la graduación nombrada resultó controvertida, porque fray Baltazar de Santa Cruz Santa, en su calidad de provincial dominico, no podía ocuparse de la comisaría, por lo cual fue reemplazado por fray Juan de los Ángeles, franciscano, en el primer lugar. Por esta razón, este último haría el juramento de los comisarios, de fidelidad y secreto, el 28 de abril de 1680 .

Como consecuencia de esta electividad, Marrón de Llano manifestó su inconformidad. Advirtió al tribunal de México que el estado de salud y la edad de 74 años de Ángeles constituían limitantes importantes para el desempeño de sus funciones. A este efecto, en 1684, pretendió documentar que el comisario no cumplía con ninguna de sus obligaciones y que no se le tenía estima por ser una persona poco entendida en los negocios inquisitoriales ni poder manejar los frecuentes conflictos de competencia con el poder civil. A pesar de que la intención de Marrón de Llano era lograr la destitución del anciano, el 8 de febrero del mismo año, el Santo Oficio de México consultó al comisario si estaba en condiciones de cumplir con sus responsabilidades y, en caso contrario, entregara el cargo a la persona que sea nombrada. Aun cuando su respuesta fue afirmativa, Marrón de Llano pretendió aprovechar la coyuntura para solicitar el nombramiento de comisario titular en tanto ocupaba el segundo lugar en la prelación, aunque la opinión pública lo tenía por persona «de dañada intención y ánimo bullicioso y inquieto». ${ }^{80}$ Ante estos hechos y en virtud de su conducta improcedente, el tribunal mexicano inició un proceso en su contra, que culminó con su destitución como comisario segundo. ${ }^{81}$

De todas maneras, este sistema de innovación en la nomenclatura de graduación pretendía establecer un orden de prelación para ocupar el oficio de manera inmediata, sin la interrupción de tiempos que afectaran

${ }^{79}$ AHN, Inquisición, 5348, n. 6; AGN, Inquisición, vol. 603, exp. 6.

${ }^{80}$ AHN, Inquisición, 5348, n. 6.

${ }^{81}$ AHN, Inquisición, 5348, n. 6. 
el funcionamiento de las comisarías. El nombramiento, no obstante, no implicaba la actuación como comisarios supernumerarios o varios comisarios que en el mismo tiempo y lugar cumplían con las mismas funciones y responsabilidades. Sin embargo, el 4 de febrero de 1765, el tribunal de México autorizó una regla general que permitía a los comisarios de las Filipinas transferir ciertas obligaciones a los comisarios segundos o terceros cuando, por "considerable distancia o impedimento legítimo», ${ }^{82}$ no pudieran llevarlas a cabo. La autorización concedida a los comisarios fue extendida a los ministros inquisitoriales de las Filipinas el 8 de julio de $1765 .{ }^{83}$ Esta medida no quiere decir que se hayan convertido en supernumerarios, sino que tenían autorización temporal para sustituir al comisario titular en determinados asuntos urgentes en la jurisdicción.

El objetivo del sistema consistió en que si algún comisario de los nombrado en los primeros lugares no podía asumir el oficio por algún motivo — edad, muerte, promoción, mudanza o desinterés — se concedía al inmediato siguiente. La ventaja de este sistema era la continuidad de las funciones de la comisaría en caso de ausencias o enfermedades del titular. La sustitución temporal —enfermedad o viaje — permitía que el titular fuera reemplazado inmediatamente por el comisario primero, segundo o tercero, siempre de la misma orden religiosa, sin necesidad de esperar el nombramiento correspondiente de México. Aun cuando alguno estuviera impedido en asumir el oficio, el siguiente podía arrogarse las responsabilidades. De ahí que, en un año, dos o tres personas distintas podían ser el comisario temporal y que, con el retorno del comisario titular, era reemplazado para volver a ocupar su lugar. El desplazamiento de un lugar distinto a la prelación implicaba que México tenía que ratificar el cambio del orden de lugares y, por lo tanto, de un año a otro puede haber diferencias que, cuando regresaba el comisario titular, volvían a su lugar original con los nombramientos anteriores a la alteración del orden. Los constantes cambios generaban la impresión de desorganización y caos. No obstante, era un complejo sistema diseñado

${ }^{82}$ AGN, Inquisición, vol. 1089, exp. 5.

${ }^{83}$ AGN, Inquisición, vol. 1089, exp. 5. 
para evitar que la ralentización de las comunicaciones se convirtiese en un distractor del funcionamiento permanente de las comisarías. Es decir, los lugares de prelación constituían un orden preventivo contra la ralentización de los nombramientos enviados desde México que evitaba la existencia de comisarías sin representación inquisitorial. La improcedencia del nombramiento podía implicar la interlocución con los inquisidores durante un largo periodo antes de que fuera efectivo. Por lo tanto, el sistema garantizaba, sin interrupciones, la continuidad administrativa.

Este sistema se aplicó de modo distinto en la elección del primer comisario de las Californias (1717). La designación en primer, segundo y tercer lugar estableció que los jesuitas Juan de Ugarte, Francisco María Piccolo y Julián de Mayorga tuvieron un orden de prelación que, ante la aceptación de Ugarte, dejó sin efecto el derecho al oficio a los otros aspirantes. ${ }^{84}$ No obstante, en caso de una pronta separación del cargo de parte de Ugarte, permitiría a Piccolo, en primer lugar, ocupar el cargo, y a Mayorga, en segundo lugar. En las Californias, es el único nombramiento de este tipo registrado en los archivos.

Aun cuando este sistema se estableció en Manila en el último tercio del siglo XVII, en las restantes comisarías su aplicación inició en las décadas siguientes. A mediados del siglo XVIII, la elección de los llamados comisarios en primer, segundo y tercer lugar estaba plenamente establecida en las comisarías de la Audiencia de Filipinas. ${ }^{85}$ En este punto, es preciso recordar que, en 1749 , la propuesta de creación de un tribunal en Filipinas sugería un sistema restitutivo de comisarios que evitara su ausencia en las jurisdicciones:

lo sucesivo, que faltando algún ministro, los superiores de cuya religión fuese, propongan a aquel tribunal tres sugetos de la misma religión para que con su informe, pueda V.S.I. nombrar al que hubiere de substituirle, subdelegando V.S.I. sus facultades en aquel tribunal para que, a proposición de los

${ }^{84}$ AGN, Inquisición, vol. 553, exp. 7; AGN, Inquisición, vol. 774, exp. 17.

${ }^{85}$ AGN, Inquisición, vol. 847, exp. 858; AGN, Inquisición, vol. 847, exp. 863; AGN, Inquisición, vol. 870, exp. 1; AGN, Inquisición, vol. 1146, exp. 8; AGN, Inquisición, vol. 1151, exp. 3; AGN, Inquisición, vol. 1241, exp. 29. 
mismos superiores, nombre sugeto que sirva interinamente, encargando sea siempre aquel de quien se haga juicio pueda tener mayor proporción a ser nombrado en propiedad. ${ }^{86}$

Los tres eclesiásticos nombrados, por lo tanto, debían pertenecer a la misma orden o, en su defecto, podía inducir a situaciones conflictivas. A propósito, en 1685, cuando el canónigo Dr. Joseph de Atienza fue electo comisario diocesano manilense, hubo discordia entre dominicos y seculares, porque la orden asumía que el oficio les pertenecía. ${ }^{87}$

En la comisaría diocesana de Manila, el sistema tenía el control de los agustinos. En la jurisdicción más importante de la Audiencia de Filipinas, hay registros que confirman la presencia de un comisario titular y tres lugares que, a mediados del siglo XVIII, fueron reemplazados por un comisario titular y dos lugares de prelación. En 1747, fray Bernardo de Ustáriz fue nombrado comisario titular después de ocupar el segundo lugar en la prelación de los nombramientos. ${ }^{88}$ La triada de sucesión, conformada por los frailes César Falle, Juan Rico de Pomozas y José de la Virgen, en primer, segundo y tercer lugar respectivamente, se alteró en 1753 cuando Falle solicitó, por problemas de salud, ocupar el segundo lugar. De tal suerte que, en el mismo año, Falle fue sustituido por Pomozas en primer lugar, Virgen ascendía a segundo lugar y fray Francisco de la Natividad Toral se incorporaba en tercer lugar. En 1755, se observaron nuevos cambios, con la presencia de fray Juan de Verea y fray Antonio Kalonge en segundo y tercer lugar. No obstante, en 1756, cuando Ustáriz se convirtió en prelado de la provincia del Santísimo Rosario, Kalonge asumió el cargo de comisario temporal, mientras que Verea y fray Pedro Luis de Sierra ocuparon el primer y tercer lugar. Al año siguiente, la renuncia definitiva de Verea promocionó a Kalonge del segundo al primer lugar y se convirtió en comisario titular. ${ }^{89}$

\footnotetext{
${ }^{86}$ Medina 1899. 148-149.

${ }^{87}$ AHN, Inquisición, 5348, n. 4; AHN, Inquisición, 2275

${ }^{88}$ AGN, Inquisición, vol. 847, exp. 863.

${ }^{89}$ AGN, Inquisición, vol. 1061, exp. 12; AGN, Inquisición, vol. 1138, exp. 22; AGN, Inquisición, vol. 847, exp. 1076; AGN, Inquisición, vol. 847, exp. 1076; AGN, Inquisición, vol. 943, exp. 3; AGN, Inquisición, vol. 932, exps. 48, 50; AGN, Inquisición,
} 
En 1761, los inquisidores solicitaron al anterior comisario, el padre Ustáriz, proponer sujetos para la provisión del tercer lugar vacante, posición que él mismo asumió hasta el año siguiente, cuando fue electo obispo de Nueva Segovia y su lugar fue ocupado por fray Carlos Masvidal. ${ }^{90}$ En 1762, cuando Sierra se convirtió en comisario titular, el sistema de sustituciones se fracturó debido a la ocupación inglesa de Manila en octubre de 1762. La coyuntura crítica afectó las actividades de la comisaría: en marzo de 1763, el comisario quemó el archivo para evitar que el invasor se apoderara de información confidencial y secreta, la aprehensión de él mismo y, el 10 de abril de 1763, la huida de la ciudad de los auxiliares, notarios y familiares, incluidos los comisarios segundo y tercero. ${ }^{91}$ Por supuesto, durante la presencia extranjera cesó la actividad inquisitorial en la capital, excepto por cartas que el comisario despachó a México.

En Nueva Segovia, como Manila, también hubo tres lugares de prelación. El comisario primero era el titular y había dos de reemplazo. Fray José Martín de Alpeñes formó parte del proceso de competencia y de promoción en la comisaría, controlada por los dominicos. En 1747, con el nombramiento de fray Gil Jiménez como comisario, Alpeñes apareció en tercer lugar. En 1750, ascendió al segundo lugar, acompañado de fray Francisco Ximénez, en tercer lugar. Los lugares también solían renovarse en caso de ausencia de uno de los comisarios. Por ello, en 1753, Ximénez fue sustituido por fray José de Viladecas en tercer lugar por sus continuas ausencias por enfermedad, condición que también presentaba el comisario Jiménez y Alpeñes. ${ }^{92}$ En este año, sin embargo, ante

vol. 847, exp. 1076; AGN, Inquisición, vol. 982, exp. 2; AGN, Inquisición, vol. 932, exps. 48 y 50 .

${ }^{90}$ AGN, Inquisición, vol. 991, exp. 7; AGN, Inquisición, vol. 929, exp. 11.

${ }^{91}$ Medina 1899. 156-157; AGN, Inquisición, vol. 1089, exp. 5. Aun cuando el comisario Sierra afirma que la huida se efectuó el 10 de abril de 1762, en esta fecha Manila todavía no era ocupada por los ingleses. Por lo tanto, esto habría ocurrido después de marzo de 1763, cuando los invasores comenzaron a fijar su atención en el Santo Oficio. El allanamiento de sus estancias, el intento fallido de apropiarse de los archivos y la detención del comisario fueron indicativos contundentes que motivaron a los auxiliares y a los comisarios segundo y tercero a huir de la ciudad.

${ }^{92}$ AGN, Inquisición, vol. 920, exp. 42; AGN, Inquisición, vol. 947, exp. 1027; AGN, Inquisición, vol. 960, exp. 2; AGN, Inquisición, vol. 958, exp. 3. 
la delicada salud del comisario y las ausencias de Alpeñes, Viladecas se convertió en comisario. En nuevos nombramientos, en 1761, figuraron los frailes Vicente García y Tomás Hernández en segundo y tercer lugar. ${ }^{93}$ En 1766, la triada fue sustituida por una dupla distinta. Fray Manuel Vélez, comisario en segundo lugar, ${ }^{94}$ se convirtió en comisario, en 1766 y en 1767, ante las ausencias y enfermedades del comisario en primer lugar, fray Tomás Marín. ${ }^{95}$ En los años siguientes, no hay registros de los sucesivos cambios en el orden, pues no se conserva información que confirman la continuidad del sistema. A la muerte del comisario fray Thomas de León, acaecida en 1781, se elevaba a esta posición a fray Antonio Calderón, dado que había figurado como comisario en segundo lugar, aunque él mismo reconoce que el despacho de su nombramiento se había perdido en el camino a Manila. No obstante, en carta recibida en el Santo Oficio de México el 27 de enero de 1784, informaba que desde que asumió las funciones, en ejercicio de derecho del oficio, no había podido cumplir con el ministerio porque había sido electo provincial de la orden dominica y, por lo tanto, de facto no había comisario diocesano en Nueva Segovia. De ahí que propusiera, en primer lugar, a fray Martín Triguero, vicario provincial y, en segundo, lugar, a fray Francisco Matoses, vicario del pueblo de Camalayucán. El 19 de agosto, los inquisidores de México despacharon al comisario de Manila para averiguar sobre la idoneidad de ambos candidatos. ${ }^{96}$

El proceso de renovación que se observa en la comisaría de la provincia de Ilocos, en el distrito de Nueva Segovia, también tuvo tres lugares, ocupados por el titular y dos reemplazos. La triada se conformaba, en 1747, por la elección de los agustinos fray Agustín Lurbes y fray Antonio Calderón, como comisarios segundo y tercero respectivamente, ${ }^{97}$ aunque fue alterada por la muerte de este último. Calderón fue sustituido, en 1753, por fray Manuel García Braseros que, dos años después, fue

93 AGN, Inquisición, vol. 847, exp. 1076; AGN, Inquisición, vol. 1033, exp. 28.

${ }^{94}$ AGN, Inquisición, vol. 736, exp. 12.

${ }^{5}$ AGN, Inquisición, vol. 847, exp. 1076; AGN, Inquisición, vol. 1065, exp. 4.

${ }^{96}$ AHN, Inquisición, 5348, n. 5.

${ }^{97}$ AGN, Inquisición, vol. 919, exp. 25. 
reemplazado a su vez por fray Manuel Garriz. ${ }^{98}$ A principios del año de 1760, los inquisidores convocaron a fray Agustín Lurbes, convertido en comisario titular del Santo Oficio, a proponer el reemplazo, por enfermedades, del tercer lugar. El orden de prelación se movió por la promoción de Garriz al segundo puesto, mientras que fray Matías Chavarría ocupó el tercer lugar. ${ }^{99}$

En la comisaría de las islas Marianas, en el distrito de Cebú, ocurrió una situación distinta. En la jurisdicción, que incluía los partidos de Agańa, Pago y Agat (Guaján) y Rota, con cabecera en San Ignacio de Agaña, tres jesuitas alemanes se distribuían los oficios de comisario y de notario. En efecto, en 1755, se concedieron nombramientos de comisario y notario: en primer lugar, a Francisco Xavier Urfahrer; en segundo, a Wolfgang Steinbeck y en tercero, a Francisco Xavier Rettenberger. ${ }^{100}$ Es importante destacar que Urfahrer era ministro en los partidos de Inarajan, Merizo y Umatac (Guaján), Steinbeck fungía en Agaña como rector del Colegio de San Juan de Letrán y Rettenberger era ministro en Rota. ${ }^{101}$ Los nombramientos de comisario en primer, segundo y tercer lugar también llevaron aparejados la concesión de notarios; de ahí que, ante la ausencia notarios, civiles o eclesiásticos, también tuvieron la responsabilidad de este cumplir con este ejercicio. Hay que recordar que el Consejo de Inquisición había autorizado, desde el 24 septiembre de 1732, que la electividad de los notarios eclesiásticos podía sustituirse cuando en el lugar no hubiese estos y, por lo tanto, elegirse para dicho oficio a un secular. ${ }^{102}$ En este sentido, la representación inquisitorial mariana se configuró para que el comisario primero actuara como comisario titular, mientras que el segundo actuase como notario. Así, el segundo y tercero podían intercalarse en las funciones de notario y de comisario según su orden de prelación. De ahí que a la muerte de

${ }^{98}$ AGN, Inquisición, vol. 1151, exp. 3; AGN, Inquisición, vol. 1138, exp. 22; AGN, Inquisición, vol. 940, exp. 5.

${ }^{99}$ AGN, Inquisición, vol. 991, exp. 6; AGN, Inquisición, vol. 1095, exp. 3.

${ }^{100}$ AGN, Inquisición, vol. 847, exp. 1076.

${ }^{101}$ AGN, Inquisición, vol. 847, exp. 1076.

${ }^{102}$ AHN, Inquisición, 2280. 
Urfahrer, en 1761, Steinbeck se convirtió en comisario y Rettenberger, en notario; ${ }^{103}$ desapareciendo automáticamente el sistema de prelaciones. En 1767, con el fallecimiento de Steinbeck, el notario asumió las funciones de comisario en virtud del mismo nombramiento que poseía como comisario-notario. No obstante, Rettenberger pereció en Agańa el 25 de octubre de 1767. Ante la ausencia de sustitutos nombrados, la comisaría de las islas Marianas quedó en suspenso y en espera de sus nuevas autoridades inquisitoriales.

A raíz de la muerte de los ministros marianos y de la expulsión de los jesuitas, en 1768, la comisaría de las islas Marianas no tenía comisarios de reemplazo. Ante la inquietud del comisario manilense por sustituir al comisario jesuita de Zamboanga y por nombrar nuevos comisarios en las islas Marianas, fray Joaquín del Rosario escribió a México para que se enviara sus respectivos nombramientos. El desconocimiento de los ministros de la orden agustina desplazados en dichos lugares y la urgencia de reemplazar títulos obligó al tribunal enviar nombramientos, para sujetos beneméritos, al comisario de Manila:

dos títulos en blanco [...] con la prevención de que constándole de la buena conducta de los actuales prelados agustinos recoletos en dichos distritos, se los embía poniendo en ellos sus nombres, dándole facultad para que en caso de muerte ó ausencia de stos pueda nombrar comisario interino en dichos parages, avisándolo en la primera ocasión que se proporcione á este tribunal. ${ }^{104}$

La concesión de la autoridad para nombrar a los comisarios titulares e interinos de Marianas y Zamboanga constituyó la confirmación de la elevada jerarquía que tenía el comisario de Manila. La singularidad de las Filipinas volvía a destacarse. A pesar de que la concesión de títulos en blanco - una práctica desconocida en cualquier otra jurisdicción - se explica por la ralentización de las comunicaciones y la urgencia de las elecciones, lo cierto es que constituyó un reconocimiento del poder que la comisaría diocesana de Manila tenía sobre todas las comisarías de las

${ }^{103}$ AGN, Inquisición, vol. 1065, exp. 5.

${ }^{104}$ AGN, Inquisición, vol. 1127, exp. 1. Sin cursivas en el original. 
islas. El tribunal de México despachó los títulos blancos el 24 de marzo de 1770; en el mes de julio siguiente, el nuevo propietario mariano ya tenía conocimiento del nombramiento concedido por Rosario, aunque su recepción tardaría más de dos años. Los agustinos recoletos, recientes eclesiásticos responsables de las islas Marianas, habían arribado ahí el 25 de agosto de 1769. Los primeros ministros en llegar fueron fray Andrés Blázquez de San Joseph y fray Antonio Sánchez de la Concepción. ${ }^{105}$

El nombramiento de comisario, por razones obvias, fue concedido al representante agustino más importante, Blázquez de San Joseph, vicario provincial y ministro en Agaña. Una vez que recibió el título, en los últimos meses de 1772, hubo de realizar el juramento de fidelidad y secreto acostumbrado ante el ministro de Agat, Sánchez de la Concepción, porque ahí no había ningún comisario ni dependiente de la Inquisición. De inmediato, también procedió a la lectura y publicación de un edicto general de fe en las iglesias marianas, excepto Rota por no haber navíos navegando en esa dirección. Aun cuando pretendió nombrar al padre Sánchez de la Concepción «con el cargo de exercer el oficio de notario en lo que pueda ocurrir, estimare sea aprovada esta mi determinación», ${ }^{106}$ no existen registros de su autorización. La desaparición de los comisarios-notarios tuvo como consecuencia que los eclesiásticos establecidos en las islas no figurasen como notarios titulares ni interinos, cuya responsabilidad se entregó al comisario manilense para que enviara de cuando en cuando a un notario para registrar en las Marianas los asuntos concernientes al Santo Oficio. Las dificultades para implementar visitas de notarios fueron comunes; de tal suerte que, en 1777, Manila advertía que no había notario que pudiera visitar las islas. ${ }^{107}$

\section{CONSIDERACIONES FINALES}

La situación periférica ultramarina de las comisarías de la Audiencia de Filipinas definió una relación de control vertical que se complejizó por la

\footnotetext{
${ }^{105}$ Coello de la Rosa 2013: 87.

${ }^{106}$ AGN, Inquisición, vol. 1189, exp. 13.

${ }^{107}$ AGN, Inquisición, vol. 1127, exp. 1.
} 
ralentización comunicativa con el tribunal del Santo Oficio de México. La singularidad filipina se observa en las relaciones de la comisaría diocesana de Manila respecto las comisarías dependientes que, a diferencia de la autonomía de las jurisdicciones novohispanas, en las islas estaban sujetas al control y trasferencia de la información de parte del comisario de Manila, único responsable y autorizado en las Filipinas para el envío y recepción de la correspondencia con el tribunal.

Ante las dificultades administrativas, procesales, de consulta, nombramientos, etc. derivados de las distancias y de la dependencia de México, que condicionaba las actividades cotidianas de las comisarías, autoridades filipinas solicitaron en varias ocasiones el establecimiento de un tribunal del Santo Oficio en Manila. A pesar de las reiteradas negativas del Consejo de Inquisición, el organismo tuvo pleno conocimiento de las dificultades existentes y, por lo tanto, se implementó medidas que únicamente se aplicaron en las comisarías filipinas.

La introducción de las comisarías dependientes en presidios, puertos de mar, villas, ciudades, provincias o islas, fue una estrategia de control del espacio. Esta medida también había sido empleada en Nueva España para dividir jurisdicciones extensas que los comisarios no podían controlar; la geografía filipina, sin embargo, tenía condiciones extremas que obstaculizaban la posibilidad de realizar visitas de distrito.

El carácter singular que reconocía las dificultades funcionales de las comisarías comenzó a aplicarse en el siglo XVII. La primera consistió en la concesión de poderes para que los reos acusados de delitos menores pudiesen recibir sentencia en Manila, sin necesidad de trasladarlos a México; con ello, los costos y los tiempos de los procesos se redujeron considerablemente. La segunda procuró evitar la interrupción de la actividad en las comisarías debido a la tardanza de los nombramientos en las sucesiones de los titulares; por este motivo, se introdujo la figura de los comisarios de primer, segundo y tercer lugar como un mecanismo de sustitución inmediata sin necesidad de esperar que los inquisidores de México enviaran el nombramiento correspondiente. 


\section{BIBLIOGRAFÍA}

Alberro, Solange. 1988. Inquisición y sociedad en México, 1571-1700. Ciudad de México: Fondo de Cultura Económica.

Araneda Riquelme, José. 2020. Un gobierno de papel. El correo y sus rutas de comunicación en tiempos de la reforma imperial en Chile (1764-1796). Santiago de Chile: Biblioteca Nacional de Chile y Centro de Investigaciones Diego Barros Arana.

Blanco Andrés, Roberto. 2018. «El cabildo eclesiástico de Manila: Entre el Patronato y la defensa de los derechos del clero secular de Filipinas (1797-1872)». En Huetz de Lemps, Javier; Gonzalo Álvarez Chillida y María-Dolores Erizalde (eds.). Gobernar colonias, administrar almas: Poder colonial y órdenes religiosas en los imperios ibéricos (1808-1930). Madrid: Casa de Velázquez, 91-114.

Brendecke, Arndt. 2016. Imperio e información. Funciones del saber en el dominio colonial español. Madrid: Iberoamericana, Vervuert.

Cadavid Arango, María Isabel. 2020. La carrera del Pacífico. Una aproximación a las relaciones comerciales entre Nueva España y Filipinas en la temprana globalización (1680-1715). Tesis de licenciatura en Historia. Medellín: Universidad de Antioquía.

Coello de la Rosa, Alexandre. 2013. «Colonialismo, resistencia e identidad chamorra en la misión post-jesuita de las islas Marianas». Estudios de Historia Novohispana. Número 49: 83-117.

Coello de la Rosa, Alexandre. 2019. «¿Por qué no hubo campañas de extirpación de idolatrías en las Filipinas (siglo XVII)?».e-Spania. Número 33. https://doi. org/10.4000/e-spania.30948

Cunningham, Charles H. 1918. "The Inquisition in the Philippines. The Salcedo Affair». The Catholical Historical Review. Volumen 3, número 4: 417-445. https://doi.org/10.2307/1896075

Descalzo Yuste, Eduardo. 2015. La Compañia de Jesús en Filipinas (1581-1768). Realidady representación. Tesis de doctorado en Historia. Barcelona: Universidad Autónoma de Barcelona. https://doi.org/10.5565/rev/nueind.6

Espinosa, Diego de 1906. «Instrucciones del Ilustrísimo Señor Cardenal, Inquisidor General, para la fundación de la Inquisición en México». En García, Genaro y Carlos Pereyra (eds.). La Inquisición de México. Documentos inéditos ó muy raros para la historia de México. Ciudad de México: Librería de la Vda. de Ch. Bouret, 215-247.

García-Abásolo, Antonio. 2005. «La difícil convivencia entre españoles y chinos en Filipinas». En Navarro García, Luis (coord.). Élites urbanas en Hispanoamérica (De la conquista a la independencia). Sevilla: Universidad de Sevilla, 487-493. 
García Garrido, Manuela Águeda. 2015. «Desobediencia y conflictos en el clero de las islas Filipinas (1595-1616)». Nuevo mundo, mundos nuevos. Número 15. https://doi.org/10.4000/nuevomundo.67689.

Medina, José Toribio. 1899. El Tribunal del Santo Oficio de la Inquisición en las islas Filipinas. Santiago de Chile: Imprenta Elzeviriana.

Miranda Ojeda, Pedro. 2019. «La configuración del territorio inquisitorial. La articulación de las comisarías diocesanas en Nueva España, 1571-1610». Itinerantes. Revista de Historia y Religión. Número 11: 151-176.

Narrativa Histórica. 2019. «Transcriptions of documentary information relevant to the voyages of the Manila Galleons, from the Archivo General de Indias, Seville, Spain». En https://www.narrativahistorica.es/wp-content/uploads/2019/12/ acapulco-manila.pdf

Palanco Aguado, Fernando. 2018. «Los primeros años de Inquisición en Filipinas. Jueces eclesiásticos, el obispo Domingo de Salazar y los comisarios agustinos fray Francisco Manrique y fray Diego Muñoz (1577-1594)». Archivo Agustiniano. Revista de estudios históricos. Volumen 102, número 220: 79-106.

Pérez-Marchand, Monelisa Lina. 2005. Dos etapas ideológicas del siglo XVIII en México a través de los papeles de la Inquisición. Ciudad de México: El Colegio de México.

Picazo Muntaner, Antoni. 2013. «Rivalidades en las redes de poder de Manila: el golpe contra el gobernador Diego de Salcedo». El futuro del pasado. Número 4: 375-388. https://doi.org/10.14201/fdp. 24762

Ramírez Méndez, Jessica y Alba Sofía Espinosa Leal. «Las provincias franciscanas descalzas en Nueva España y Filipinas». En Martínez López-Cano, María del Pilar y Francisco Javier Cervantes Bello (coords.). La iglesia y sus territorios, siglos XVI-XVIII. Ciudad de México: Instituto de Investigaciones Históricas y Universidad Nacional Autónoma de México: 151-180.

Real Díaz, José. 1970. Estudio diplomático del documento indiano. Sevilla: Escuela de Estudios Hispano-Americanos.

Rodrigues Lourenço, Miguel. 2019. «¿Gestión de la distancia o reajuste de jurisdicciones? La propuesta de la creación de un tribunal del Santo Oficio en las Filipinas por el jesuita Francisco Velho». Histórica. Volumen 43, número 2: 17-58. https://doi.org/10.18800/historica.201902.001

Rodrigues Lourenço, Miguel. 2020. «El léxico de la representación inquisitorial en Filipinas (1581-1671)». Ponencia presentada en el Coloquio Internacional Inquisición y periferias. Santiago de Chile.

Sales Colín, Ostwald. 2000. «La Inquisición en Filipinas: el caso de Mindanao y Manila, siglo XVII». En Quezada, Noemí; Martha Rodríguez y Marcela Suárez (eds). Inquisición novohispana. Volumen 1. Ciudad de México: Universidad Nacional Autónoma de México y Universidad Autónoma Metropolitana: 255-270. 
Vassallo, Jaqueline. 2019. «Consideraciones sobre sobre el problema de las fuentes judiciales inquisitoriales para el estudio de la Inquisición en América. El caso del tribunal de Lima». Temas Americanistas. Número 42: 51-68.

Vázquez de Espinosa, Antonio. 1948. Compendio y descripción de las Indias Occidentales. Washington: Smithsonian Institution.

Fecha de recepción: 26/VIII/2021

Fecha de aceptación: 22/IX/2021 